\title{
Approximate Modeling of Unsteady Aerodynamics for Hypersonic Aeroelasticity
}

\author{
Jack J. McNamara* and Andrew R. Crowelli \\ Ohio State University, Columbus, Ohio 43210 \\ and \\ Peretz P. Friedmann,, Bryan Glaz,,$\underline{\S}$ and Abhijit Gogulapati $\mathbb{I}$ \\ University of Michigan, Ann Arbor, Michigan 48109
}

DOI: $\underline{10.2514 / 1 . C 000190}$

\begin{abstract}
Various approximations to unsteady aerodynamics are examined for the aeroelastic analysis of a thin doublewedge airfoil in hypersonic flow. Flutter boundaries are obtained using classical hypersonic unsteady aerodynamic theories: piston theory, Van Dyke's second-order theory, Newtonian impact theory, and unsteady shock-expansion theory. The theories are evaluated by comparing the flutter boundaries with those predicted using computational fluid dynamics solutions to the unsteady Navier-Stokes equations. In addition, several alternative approaches to the classical approximations are also evaluated: two different viscous approximations based on effective shapes and combined approximate computational approaches that use steady-state computational-fluid-dynamics-based surrogate models in conjunction with piston theory. The results indicate that, with the exception of first-order piston theory and Newtonian impact theory, the approximate theories yield predictions between 3 and $17 \%$ of normalized root-mean-square error and between 7 and $40 \%$ of normalized maximum error of the unsteady Navier-Stokes predictions. Furthermore, the demonstrated accuracy of the combined steady-state computational fluid dynamics and piston theory approaches suggest that important nonlinearities in hypersonic flow are primarily due to steadystate effects. This implies that steady-state flow analysis may be an alternative to time-accurate Navier-Stokes solutions for capturing complex flow effects.
\end{abstract}

\section{Nomenclature}

$\left\{\mathbf{A}_{\mathbf{p}}\right\} \quad=$ estimated aeroelastic system matrix

$a=$ nondimensional offset between the elastic axis and the midchord, positive for elastic-axis locations behind midchord

$a_{o}, a_{i}, \quad=$ coefficients used for damping and frequency

$b_{i}, A_{i} \quad$ identification

$a_{\infty} \quad=$ speed of sound

$\begin{array}{ll}a_{\infty} & = \\ C & \text { semichord, }(c / 2)\end{array}$

$C(x) \quad=$ local deviations of kriging model

$C_{L, \mathrm{SS}}, \quad=$ static component of lift coefficient computed using

$C_{L, \mathrm{SUR}}$ a computational fluid dynamics and a computational-fluid-dynamics-based surrogate

$C_{M, S S}, \quad=$ static component of moment coefficient about the

$C_{M, \mathrm{SUR}_{S S}} \quad$ midchord computed using a computational fluid dynamics and a computational-fluid-dynamicsbased surrogate

$C_{p} \quad=$ pressure coefficient

$\left\{\underline{\mathbf{C}}_{\mathbf{p}}\right\} \quad=$ estimated aeroelastic system matrix

$\bar{C}_{p}$

\begin{tabular}{|c|c|c|}
\hline$C_{p, S S}$ & $=$ & $\begin{array}{l}\text { component of piston theory pressure due strictly } \\
\text { to surface inclination }\end{array}$ \\
\hline$C_{p, \text { vel }}$ & $=$ & $\begin{array}{l}\text { component of piston theory pressure due strictly } \\
\text { to surface velocity }\end{array}$ \\
\hline$c$ & $=$ & chord length, reference length \\
\hline$c_{l}, c_{m}$ & $=$ & $\begin{array}{l}\text { coefficients of lift and moment about the } \\
\text { elastic axis }\end{array}$ \\
\hline$F_{Z}$ & $=$ & flutter prediction parameter \\
\hline$F^{-}(j)$ & $=$ & $\begin{array}{l}\text { intermediate function used to compute the flutter } \\
\text { prediction parameter }\end{array}$ \\
\hline$h$ & $=$ & plunge degree of freedom of the airfoil \\
\hline$h_{i}$ & $=$ & $\begin{array}{l}\text { states in state-space representation of } \\
\text { autoregressive model }\end{array}$ \\
\hline $\mathbf{K}$ & $=$ & diagonal generalized stiffness matrix \\
\hline$K_{h}, K_{\alpha}$ & & spring constants in pitch and plunge \\
\hline & & discrete time \\
\hline$L$ & $=$ & sectional lift force \\
\hline$L_{\infty}$ & $=$ & normalized maximum error \\
\hline M & $=$ & diagonal generalized mass matrix \\
\hline$M_{E A}$ & $=$ & $\begin{array}{l}\text { sectional aerodynamic moment about the } \\
\text { elastic axis }\end{array}$ \\
\hline$M_{f}$ & $=$ & flutter Mach number \\
\hline$M_{\infty}$ & $=$ & freestream Mach number \\
\hline m & $=$ & Mass \\
\hline$n_{m}$ & $=$ & number of modes \\
\hline$p, p_{\infty}$ & $=$ & pressure and freestream pressure \\
\hline & $=$ & vector of generalized forces \\
\hline $\mathbf{q}$ & $=$ & vector of generalized degrees of freedom \\
\hline$q_{i}$ & $=$ & generalized displacements \\
\hline $\begin{array}{l}q_{\infty}, q_{f} \\
R\end{array}$ & $\begin{array}{l}= \\
=\end{array}$ & $\begin{array}{l}\text { dynamic pressure and dynamic pressure at flutter } \\
\text { gas constant for air }\end{array}$ \\
\hline$R(x)$ & $=$ & global approximation of kriging model \\
\hline$r$ & $=$ & real part of eigenvalue \\
\hline$r_{\alpha}$ & $=$ & nondimensional radius of gyration of the airfoil \\
\hline$S$ & & sample sites of the parameter space \\
\hline$S_{\alpha}$ & & airfoil static imbalance \\
\hline & $=$ & imaginary part of eigenvalue \\
\hline$T_{e}$ & $=$ & sample time \\
\hline & & \\
\hline
\end{tabular}

Received 18 November 2009; revision received 24 August 2010; accepted for publication 26 August 2010. Copyright (C) 2010 by J. McNamara, A. Crowell, P. Friedmann, B. Glaz, and A. Gogulapati.. Published by the American Institute of Aeronautics and Astronautics, Inc., with permission. Copies of this paper may be made for personal or internal use, on condition that the copier pay the $\$ 10.00$ per-copy fee to the Copyright Clearance Center, Inc., 222 Rosewood Drive, Danvers, MA 01923; include the code 0021-8669/ 10 and $\$ 10.00$ in correspondence with the CCC.

*Assistant Professor, Department of Mechanical \& Aerospace Engineering, E440 Scott Laboratory, 201 West 19th Avenue. Senior Member AIAA.

${ }^{\top} \mathrm{Ph} . \mathrm{D}$. Candidate, Department of Mechanical \& Aerospace Engineering, N350 Scott Laboratory, 201 West 19th Avenue. Student Member AIAA.

FFrançois-Xavier Bagnoud Professor, Department of Aerospace Engineering, 3001 FXB Building, 1320 Beal Avenue. Fellow AIAA.

${ }^{\S}$ Postdoctoral Fellow, Department of Aerospace Engineering, 3001 FXB Building, 1320 Beal Avenue. Member AIAA.

TPh.D. Candidate, Department of Aerospace Engineering, 3001 FXB Building, 1320 Beal Avenue. Student Member AIAA. 


\begin{tabular}{|c|c|}
\hline$V_{\infty}$ & $=$ freestream velocity \\
\hline$v_{n}$ & $=$ normal velocity of airfoil surfaces \\
\hline$W$ & $\begin{aligned}= & \text { snapshot matrix, computational fluid dynamics } \\
& \text { response data to } \mathrm{s}\end{aligned}$ \\
\hline$w_{d}$ & $=$ displacement of the surface of the structure \\
\hline$X_{j}, Y_{j}$ & flutter parameter matrices \\
\hline$\left\{X_{p}\right\}$ & $=$ state matrix \\
\hline$x, y, z$ & $=$ spatial coordinates \\
\hline$x_{\text {rot }}$ & $\begin{array}{l}=\text { point about which airfoil angle of attack is } \\
\text { measured }\end{array}$ \\
\hline$x_{\alpha}$ & $\begin{array}{l}=\text { nondimensional offset between the elastic axis and } \\
\text { the cross-sectional center of gravity }\end{array}$ \\
\hline$y(x)$ & kriging approximation \\
\hline$Z(x, t)$ & position of structural surface \\
\hline$Z_{\text {str }}(x)$ & function describing surface geometry \\
\hline$\alpha$ & pitch degree of freedom \\
\hline$\alpha_{s}$ & angle of attack \\
\hline$\gamma$ & $=$ ratio of specific heats \\
\hline$\delta^{k-1}$ & $\begin{array}{l}=\text { input for autoregressive moving-average model of } \\
\text { aeroelastic system }\end{array}$ \\
\hline$\zeta$ & damping ratio \\
\hline$\Lambda$ & estimated matrix eigenvalue \\
\hline$\mu_{m}$ & airfoil mass ratio \\
\hline$\rho$ & $=$ air density \\
\hline$\tau$ & slope of the airfoil surface \\
\hline$\phi_{i}$ & $=$ vector of displacements for mode $i$ \\
\hline$\omega$ & $=$ frequency \\
\hline$\omega_{h}$ & $\begin{aligned}= & \text { frequency corresponding to stiffness associated } \\
& \text { with the plunge degree of freedom of the airfoil }\end{aligned}$ \\
\hline$\omega_{\alpha}$ & $\begin{array}{l}=\text { frequency corresponding to stiffness associated } \\
\text { with the pitch degree of freedom of the airfoil }\end{array}$ \\
\hline
\end{tabular}

\section{Introduction}

$\mathbf{H}$ ISTORICALLY, the development of airbreathing hypersonic vehicles has encountered difficulties due in part to the inability to survive the extreme temperatures associated with prolonged hypersonic flight. This is reflected by the cancellation of several past hypersonic vehicle programs, such as the National Aerospace Plane $[1,2]$ of the 1980s and the VentureStar reusable launch vehicle program [2] of the 1990s. Despite previous setbacks, the need for low-cost reusable launch vehicles and the desire of the US Air Force for unmanned hypersonic vehicles, continues to sustain research in hypersonic vehicle technologies [3-11].

Hypersonic vehicle configurations will consist of long, slender lifting-body designs, where the body and aerodynamic control surfaces are flexible due to minimum-weight restrictions. Furthermore, these vehicles operate [12-15] over a Mach number range of 0 to 15 and must fly within the atmosphere for sustained periods of time to meet the needs of an airbreathing propulsion system [16]. The combined extreme aerodynamic heating and loading acting on the airframe produces complex interactions between the flow, flight dynamics, structural response, controllers, and propulsion system. These interactions have received only limited attention in the past [17-20]. Moreover, the impracticality to test aeroelastically and aerothermoelastically scaled models in wind-tunnels [21], a common practice in the subsonic and supersonic flow regime, implies that aeroelastic simulations are critical for this flight regime.

A challenging aspect in computational aeroelastic analysis of hypersonic vehicles is accurate and efficient modeling of the unsteady aerodynamic forces. Historically, due to the limited capabilities of computational facilities, past work has used a number of approximate unsteady aerodynamic theories, each of which assume inviscid flow and neglect real-gas effects [22-29]. Computational efficiency and ease of implementation make these methods attractive for preliminary design and sensitivity analysis of hypersonic configurations $[13,30-34]$. However, systematic evaluation of these approaches is needed to provide a general characterization of their accuracy in hypersonic flow. At the other end of the spectrum, advances in computing capabilities have enabled the use of computational fluid dynamics (CFD) modeling of unsteady aerodynamics in hypersonic aeroelastic studies $[34,35]$. However, such approaches remain impractical for detailed aerothermoelastic analysis over an extended trajectory $[34,36,37]$. Thus, another important issue is identification of new modeling approaches for unsteady hypersonic aerodynamics that provide adequate fidelity in cases where classical approximate approaches become unreliable.

The quasi-steady [38] nature of hypersonic flowfields (where wake effects can be ignored, since disturbances cannot propagate upstream) has motivated study on the incorporation of steady-state CFD flow analysis into unsteady aerodynamic models $[36,39,40]$. The potential to use steady-state flow analysis is appealing because it provides a means to capture complex flow phenomena neglected by classical aerodynamic theories, is not limited by the geometry of the surface, and is significantly more computationally efficient than time-accurate CFD analysis. Such an approach was investigated by Scott and Pototzky [36] using steady CFD to develop a quasi-steady hypersonic aerodynamic model. Separate solutions for the static and harmonic portions of the pressure were obtained using boundary conditions reflecting the unsteadiness of the flow. The static component of pressure was computed over each deflected mode shape. For the harmonic component of pressure, two different approaches were investigated. One approach used a transpiration boundary condition. The other computed an effective deflected mode shape using the expression for wash velocity to relate surface geometry to surface velocity. The method was evaluated using a wing operating at Mach numbers of 5, 10, and 15 and reduced frequencies of 0.05. Comparisons with unsteady CFD computations demonstrated improvement in the aerodynamic loads using the CFD-based quasi-steady aerodynamics relative to piston theory [36]. However, it is not clear if first-, second-, or third-order piston theory was used for comparison with the quasi-steady CFD aerodynamics.

In a recent hypersonic aeroelastic study [39], steady-state CFD flow analysis was used to approximate the unsteady aerodynamic loads by computing the generalized aerodynamic forces (GAFs) as purely a function of the instantaneous surface inclination to the flow. This approximation was based on the hypothesis that the GAFs in hypersonic flow are a strong nonlinear function of the structural displacement (i.e., instantaneous inclination to the flow) and a weak function of the velocity of displacement (i.e., wash velocity). Note that the effect of structural displacement leads to aerodynamic stiffness terms, while wash velocity leads to aerodynamic damping terms. The impact of neglecting aerodynamic damping terms on the aeroelastic response was investigated by considering the flutter of a simple two-degree-of-freedom double-wedge airfoil using thirdorder piston theory and both steady and unsteady Navier-Stokes aerodynamics. It was concluded that the neglect of the wash velocities on the pressure increased the error of the steady-state CFD approach beyond that of the simpler third-order piston theory approximation. Thus, it is evident that aerodynamic damping remains important for aeroelastic analysis in hypersonic flows.

The overall goal of this paper is to systematically evaluate several approximate unsteady hypersonic aerodynamic models suitable for aeroelastic analysis. The specific objective is to provide a comparison of hypersonic aeroelastic flutter boundaries, computed for the double-wedge typical section shown in Fig. 1, using both approximate models and CFD solutions to the unsteady Navier-Stokes (NS) equations. The approximate models considered are 1) piston theory

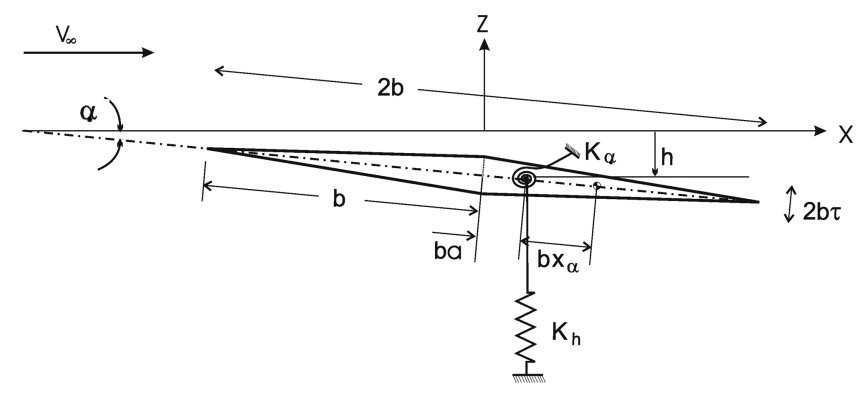

Fig. 1 Two-degree-of-freedom typical section geometry. 
(PT), 2) Van Dyke's second-order theory (VD), 3) an unsteady shock-expansion method (SE), 4) unsteady Newtonian impact theory (NI), 5) the approximation of viscous effects with piston theory using effective shape corrections, and 6) a static CFD approximation corrected for unsteady effects. Note that the focus of this work is on modeling of the unsteady GAFs. Thus, the effects of aerodynamic heating are not considered.

\section{Approximate Aerodynamic Models}

The approximate models considered in this paper are briefly described in this section.

\section{A. Piston Theory}

Piston theory was developed by Lighthill [22], who noted that at high Mach numbers the shock waves and expansion fans on an airfoil form at small angles to the undisturbed flow. This implies that streamwise gradients are small compared to gradients perpendicular to the flow. Furthermore, since velocity components parallel to shock waves and expansion fans are unchanged, the component of disturbances perpendicular to the flow are large compared to the component of disturbances parallel to the flow. Consequently, any plane slab of fluid that is initially perpendicular to the undisturbed flow remains perpendicular as it moves both downstream and in its own plane under the laws of one-dimensional unsteady motion $[22,41]$. This realization of the flow is based on the Hayes equivalence principle [41], which states that "a rotational hypersonic flow on a slender body is equivalent to an unsteady flow in a space having one dimension less."

\section{Classical Piston Theory}

Using this approximation of the flow, the position of a portion of solid wall bounding a slab of fluid moves normal to the flow with the velocity $v_{n}$ such that

$$
v_{n}=\frac{\partial Z(x, t)}{\partial t}+V_{\infty}\left\{\frac{\partial Z(x, t)}{\partial x}\right\}
$$

where

$$
Z(x, t)=w_{d}(x, t)+Z_{\text {str }}(x)+\left(x_{\text {rot }}-x\right) \alpha_{s}
$$

and from Fig. 1,

$$
w_{d}(x, t)=-\{h(t)+(x-b a) \alpha(t)\}
$$

Note that $V_{\infty}$, the velocity of the freestream, is the approximate velocity of the slab of fluid as it moves downstream. This characterization of the flow implies that the change in pressure on the surface of a vehicle is analogous to a piston moving in a onedimensional channel $[\underline{22}, \underline{23}]$, as shown in Fig. $\underline{2}$.

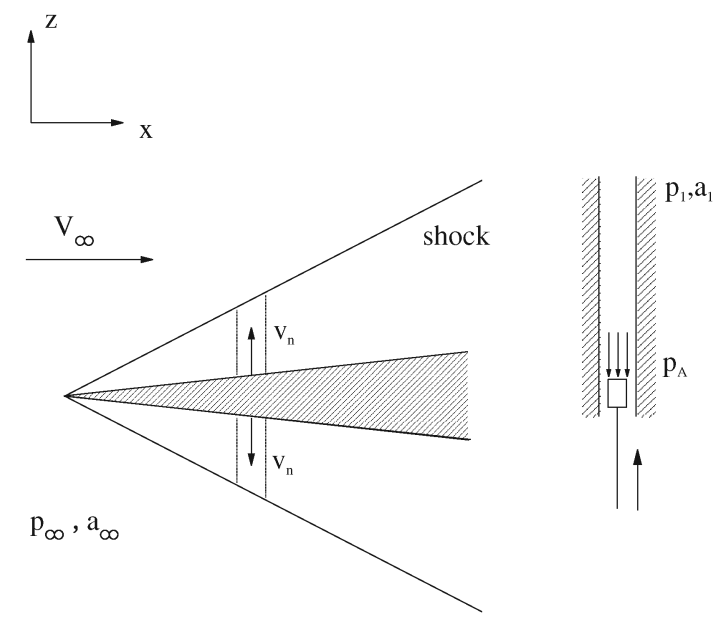

Fig. 2 Model for loading on an equivalent piston.
Assuming the piston generates only simple waves and no changes in entropy, the local pressure, denoted by $p(x, t)$, is therefore

$$
\frac{p(x, t)}{p_{\infty}}=\left(1+\frac{\gamma-1}{2} \frac{v_{n}}{a_{\infty}}\right)^{\frac{2 \gamma}{(\gamma-1)}}
$$

Note that use of Eq. (4) assumes no shock is present. Lighthill [22] demonstrates that a third-order binomial expansion of Eq. (4) in terms of $v_{n} / a_{\infty}$ yields errors within $6 \%$ of both the simple wave and shock-expansion predictions of pressure. Furthermore, this error is less than the difference between the simple wave prediction of Eq. (4) and the shock-expansion pressure [22]. Thus, the pressure coefficient on an oscillating surface is given by the following simple pointfunction relationship:

$$
C_{p}(x, t)=\frac{2}{M_{\infty}^{2}}\left\{\frac{v_{n}}{a_{\infty}}+\frac{(\gamma+1)}{4}\left(\frac{v_{n}}{a_{\infty}}\right)^{2}+\frac{(\gamma+1)}{12}\left(\frac{v_{n}}{a_{\infty}}\right)^{3}\right\}
$$

Note that this derivation assumes that the freestream Mach number is sufficiently large and the magnitude of the normal component of fluid velocity never exceeds the speed of sound in the undisturbed fluid $[\underline{22}, \underline{23}]$ : i.e.,

$$
M_{\infty}^{2} \gg 1 \text { and } M_{\infty}\left[\tau+\left(\frac{w_{d \max }}{c}\right)\left(\frac{\omega_{\max } c}{V_{\infty}}\right)\right]<1
$$

Thus, the accuracy of the piston theory pressure diminishes with increasing Mach number and surface inclination to the freestream $[\underline{22}, \underline{23}, \underline{28}]$.

\section{Local Piston Theory}

For problems that exhibit significant three-dimensional flow and/ or high Mach numbers and surface inclinations, Eqs. (1) and (5) can be modified by replacing freestream flow quantities with locally computed flow quantities from a steady-state flow analysis. This modified approach is known as local piston theory (LPT) $[\underline{27}, \underline{40}, \underline{42}, \underline{43}]$. Note that for LPT, the thickness $Z_{\text {str }}$ and static angle-of-attack $\alpha_{s}$ terms in Eq. (2) must be deleted, since the flow is locally parallel to the surface after the steady-state flow analysis. Thus, for local piston theory, Eqs. (1), (2), and (ㅁ) become, respectively,

$$
\begin{gathered}
v_{n}=\frac{\partial Z(x, t)}{\partial t}+V_{\text {local }}\left\{\frac{\partial Z(x, t)}{\partial x}\right\} \\
Z(x, t)=w_{d}(x, t)
\end{gathered}
$$

$C_{p}(x, t)=\frac{2}{M_{\text {local }}^{2}}\left\{\frac{v_{n}}{a_{\text {local }}}+\frac{(\gamma+1)}{4}\left(\frac{v_{n}}{a_{\text {local }}}\right)^{2}+\frac{(\gamma+1)}{12}\left(\frac{v_{n}}{a_{\text {local }}}\right)^{3}\right\}$

\section{B. Van Dyke's Second-Order Theory}

Van Dyke's supersonic second-order theory $[24,27]$ is an approximate aerodynamic theory commonly used in supersonic and hypersonic research. Assuming irrotational flow, the nonlinear velocity potential equation is given by

$$
\begin{aligned}
& \left(a_{l}^{2}-\tilde{\Omega}_{x}^{2}\right) \tilde{\Omega}_{x x}+\left(a_{l}^{2}-\tilde{\Omega}_{y}^{2}\right) \tilde{\Omega}_{y y}+\left(a_{l}^{2}-\tilde{\Omega}_{z}^{2}\right) \tilde{\Omega}_{z z}-2 \tilde{\Omega}_{y} \tilde{\Omega}_{z} \tilde{\Omega}_{y z} \\
& \quad-2 \tilde{\Omega}_{x} \tilde{\Omega}_{z} \tilde{\Omega}_{x z}-2 \tilde{\Omega}_{x} \tilde{\Omega}_{y} \tilde{\Omega}_{x y}=0
\end{aligned}
$$

where $\tilde{\Omega}$ is the nonlinear velocity potential; $a_{l}$ is the local speed of sound; and subscripts $x, y$, and $z$ denote differentiation with respect to $x, y$, and $z$, respectively. The local speed of sound is related to $a_{\infty}$ by

$$
a_{l}^{2}=a_{\infty}^{2}-\frac{\gamma-1}{2}\left(\tilde{\Omega}_{x}^{2}+\tilde{\Omega}_{y}^{2}+\tilde{\Omega}_{z}^{2}-V_{\infty}^{2}\right)
$$




$$
\tilde{\Omega}=V_{\infty}\left(x+\Phi_{\text {pot }}\right)
$$

so that

$$
\begin{aligned}
& \Phi_{\mathrm{pot}, y y}+\Phi_{\mathrm{pot}, z z}-\beta^{2} \Phi_{\mathrm{pot}, x x}=M_{\infty}^{2}\left\{\frac { \gamma - 1 } { 2 } \left(2 \Phi_{\mathrm{pot}, x}+\Phi_{\mathrm{pot}, x}^{2}\right.\right. \\
& \left.+\Phi_{\mathrm{pot}, y}^{2}+\Phi_{\mathrm{pot}, z}^{2}\right)\left(\Phi_{\mathrm{pot}, x x}+\Phi_{\mathrm{pot}, y y}+\Phi_{\mathrm{pot}, z z}\right)+2 \Phi_{\mathrm{pot}, x} \Phi_{\mathrm{pot}, x x} \\
& +\Phi_{\mathrm{pot}, x}^{2} \Phi_{\mathrm{pot}, x x}+\Phi_{\mathrm{pot}, y}^{2} \Phi_{\mathrm{pot}, y y}+\Phi_{\mathrm{pot}, z}^{2} \Phi_{\mathrm{pot}, z z} \\
& +2 \Phi_{\mathrm{pot}, y} \Phi_{\mathrm{pot}, z} \Phi_{\mathrm{pot}, y z}+2 \Phi_{\mathrm{pot}, x}\left(1+\Phi_{\mathrm{pot}, z}\right) \Phi_{\mathrm{pot}, z x} \\
& \left.+2\left(1+\Phi_{\mathrm{pot}, x}\right) \Phi_{\mathrm{pot}, y} \Phi_{\mathrm{pot}, x y}\right\}
\end{aligned}
$$

where $\beta=\sqrt{M^{2}-1}$. Equation (13) is solved using an iterative procedure. The first-order solution is obtained by neglecting nonlinear terms of $\Phi_{\text {pot }}$ derivatives in Eq. (13). This yields the wave equation:

$$
\Phi_{\mathrm{pot}, y y}^{(1)}+\Phi_{\mathrm{pot}, z z}^{(1)}-\beta^{2} \Phi_{\mathrm{pot}, x x}^{(1)}=0
$$

This linearized solution is then substituted into the right-hand side of Eq. (13) in order to determine the second-order solution.

The first-order equation of two-dimensional supersonic flow is given by

$$
\Phi_{\mathrm{pot}, z z}^{(1)}-\beta^{2} \Phi_{\mathrm{pot}, x x}^{(1)}=0
$$

The general solution is given by

$$
\Phi_{\text {pot }}^{(1)}(x, z)=a^{(1)}(x-\beta z)+b^{(1)}(x+\beta z)
$$

where $a^{(1)}$ and $b^{(1)}$ are determined from the first-order boundary conditions. Substituting Eq. (16) into Eq. (13) and neglecting thirdorder-and-higher terms yields

$$
\begin{aligned}
& \Phi_{\mathrm{pot}, z z}^{(2)}-\beta^{2} \Phi_{\mathrm{pot}, x x}^{(2)}=2 M_{\infty}^{2}\left\{\left(\frac{(\gamma+1) M_{\infty}^{2}}{2 \beta^{2}}-1\right) \beta^{2} \Phi_{\mathrm{pot}, x}^{(1)} \Phi_{\mathrm{pot}, x x}^{(1)}\right. \\
& \left.+\Phi_{\mathrm{pot}, z}^{(1)} \Phi_{\mathrm{pot}, x z}^{(1)}\right\}
\end{aligned}
$$

The solution to Eq. (17) for flow past a single boundary (i.e., one surface of an airfoil) is then given by

$$
\begin{gathered}
\Phi_{\mathrm{pot}}^{(2)}(x, z)=a^{(2)}(x-\beta z)+b^{(2)}(x+\beta z) \\
+\frac{(\gamma+1) M_{\infty}^{4}}{4 \beta^{2}} z \Phi_{\mathrm{pot}, x}^{(1)} \Phi_{\mathrm{pot}, z}^{(1)}
\end{gathered}
$$

where $a^{(2)}$ and $b^{(2)}$ are determined from the second-order boundary conditions. For flow past a curved surface, shown in Fig. 3, the surface is defined by a continuous function:

$$
z=\bar{\epsilon} Z(x)
$$

where $\bar{\epsilon} \ll 1$ and $Z(x) \sim \mathcal{O}(1)$. The solution to the first-order problem is given by

$$
\Phi_{\mathrm{pot}}^{(1)}=-\bar{\epsilon} \frac{Z(x-\beta z)}{\beta}
$$

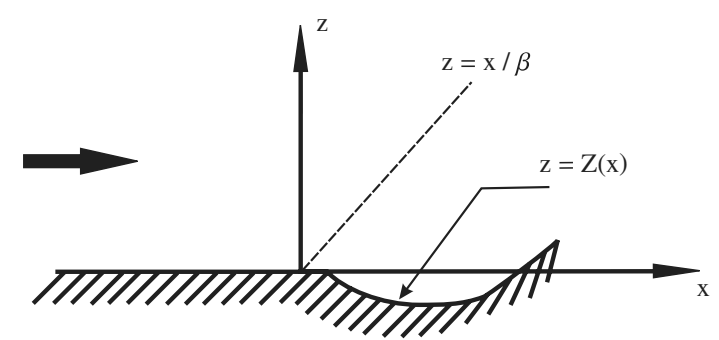

Fig. 3 Flow past a curved wall [24]. and the second-order perturbation potential is given by

$$
\begin{aligned}
\Phi_{\mathrm{pot}}^{(2)} & =-\bar{\epsilon} \frac{Z(x-\beta z)}{\beta}-\bar{\epsilon}^{2}\left\{Z(x-\beta z) \frac{\partial Z(x-\beta z)}{\partial(x-\beta z)}\right. \\
& +\frac{(\gamma+1) M_{\infty}^{4}}{4 \beta^{3}} z\left(\frac{\partial Z(x-\beta z)}{\partial(x-\beta z)}\right)^{2} \\
& \left.+\left(\frac{M_{\infty}^{2}}{2 \beta^{2}}\right)\left(\frac{(\gamma+1) M_{\infty}^{2}}{2 \beta^{2}}-2\right) \int_{0}^{x-\beta z}\left(\frac{\partial Z(\xi)}{\partial \xi}\right)^{2} \mathrm{~d} \xi\right\}
\end{aligned}
$$

The velocity components of the flow are determined from the potential field given in Eq. (21):

$$
u / V_{\infty}=\Phi_{\text {pot }, x} \quad v / V_{\infty}=\Phi_{\text {pot }, y} \quad w / V_{\infty}=\Phi_{\text {pot }, z}
$$

Assuming isentropic flow, the pressure coefficient is then given by

$$
C_{p}=\frac{2}{\gamma M_{\infty}^{2}}\left\{\left(1+\frac{\gamma-1}{2} M_{\infty}^{2}\left(1-\frac{\left(V_{\infty}+u\right)^{2}+v^{2}+w^{2}}{V_{\infty}^{2}}\right)\right)^{\frac{\gamma}{\gamma-1}}-1\right\}
$$

Using Eqs. (21-23) and neglecting terms of $\bar{\epsilon}^{3}$ and higher, the pressure coefficient is given by

$$
C_{p}(x)=\frac{2}{\beta} \bar{\epsilon} \frac{\partial Z(x)}{\partial x}+\frac{(\gamma+1) M_{\infty}^{4}-4 \beta^{2}}{2 \beta^{4}}\left(\bar{\epsilon} \frac{\partial Z(x)}{\partial x}\right)^{2}
$$

If the local steady angle of attack, given by $\bar{\epsilon}(\partial Z(x) / \partial x)$, is replaced by the quasi-steady angle of attack, which for thin bodies is given by $v_{n} / V_{\infty}$, the pressure coefficient is $[\underline{27}, \underline{33}]$

$$
C_{p}(x, t)=\frac{2}{M_{\infty}^{2}}\left\{\frac{M_{\infty}}{\beta} \frac{v_{n}}{a_{\infty}}+\frac{M_{\infty}^{4}(\gamma+1)-4 \beta^{2}}{4 \beta^{4}}\left(\frac{v_{n}}{a_{\infty}}\right)^{2}\right\}
$$

Despite the fact that each expression was derived using a different approach, a comparison between the Van Dyke second-order quasisteady pressure coefficient, Eq. (25), and Lighthill's piston theory expression, Eq. (5), reveals similar expressions. Considering only the first- and second-order terms in Eq. (5), the main difference is the introduction of $\beta$ in the coefficients of Eq. (25). However, note that for increasing Mach number, $\beta \rightarrow M_{\infty}$, and the two expressions become identical. Because of the similarity of the expressions for pressure, Van Dyke's theory is also sometimes referred to as piston theory. However, it is important to distinguish between the two theories, since they are developed using different approaches.

\section{Unsteady Hypersonic Shock-Expansion Method}

Shock-expansion theory is a simple method for determining various fluid quantities as the flow passes through shocks and expansion fans that occur on a given shape [44]. For the doublewedge airfoil in steady hypersonic flow shown in Fig. $\underline{4}$, the oblique

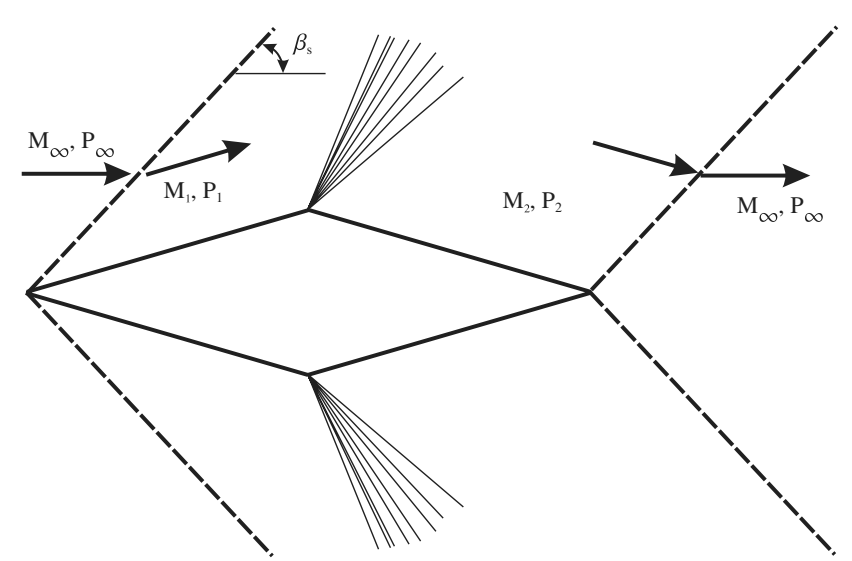

Fig. 4 Oblique shocks and expansion fans on a double-wedge airfoil [44]. 
shock waves are at the leading edge and trailing edge, while expansion fans occur at the midchord.

The basic procedure of the shock-expansion method $[1,26]$ consists of the following:

1) Computing the Mach number and pressure behind the oblique shock at the nose using the wedge angle at the leading edge of the body: i.e., $\theta_{N}$.

2) Assuming that the flow is in isentropic expansion along the surface downstream of the leading edge, the turning angle of the flow, denoted by $\Delta \theta$, is calculated from

$$
\Delta \theta(x)=\theta_{l}(x)-\theta_{N}
$$

where $\theta_{l}(x)$ is the local angle of inclination of the body at a given $x$ position along the airfoil.

The shock angle $\beta_{s}$, required in order to calculate the Mach number and pressure behind the oblique shock, is obtained using a nonlinear relation:

$$
\tan \theta_{N}=2 \cot \beta_{s}\left\{\frac{M_{\infty}^{2} \sin ^{2} \beta_{s}-1}{M_{\infty}^{2}\left(\gamma+\cos 2 \beta_{s}\right)+2}\right\}
$$

Only the normal component of fluid velocity is affected by an oblique shock wave; therefore, the Mach number $M_{N}$ and pressure $p_{N}$ behind the shock are determined using normal shock relations:

$$
\frac{p_{N}}{p_{\infty}}=\left\{1+\frac{2 \gamma}{\gamma+1}\left(M_{\infty}^{2} \sin ^{2} \beta_{s}-1\right)\right\}
$$

and

$$
M_{N}=\frac{1}{\sin \left(\beta_{s}-\theta_{N}\right)} \sqrt{\frac{M_{\infty}^{2} \sin ^{2} \beta_{s}+\left(\frac{2}{\gamma-1}\right)}{\left(\frac{2}{\gamma-1}\right) M_{\infty}^{2} \sin ^{2} \beta_{s}-1}}
$$

Finally, the pressure at any point along the surface of a body is determined from $\Delta \theta(x), M_{N}$, and $p_{N}$, using the Prandtl-Meyer expansion formula:

$$
p(x)=p_{N}\left\{1+\frac{\gamma-1}{2} M_{N} \Delta \theta(x)\right\}^{\frac{2 \gamma}{\gamma-1}}
$$

In [26], the extension of these relations to unsteady flow is discussed. This is accomplished using a similar approach to that of [27,33], where the expression for the steady pressure was extended to an unsteady pressure by replacing the steady inclination angle of the airfoil surface in Eqs. (27-30) with the quasi-steady inclination: i.e.,

$$
\theta_{N}(t)=\tan ^{-1} \frac{v_{n}\left(x_{N}, t\right)}{V_{\infty}} \quad \theta_{l}(x, t)=\tan ^{-1} \frac{v_{n}(x, t)}{V_{\infty}}
$$

Combining Eqs. (26-31), the pressure coefficient for unsteady hypersonic shock-expansion theory is given by

$$
C_{p}(x, t)=\frac{2}{\gamma M_{\infty}^{2}}\left\{\left(\frac{p_{N}}{p_{\infty}}\right)\left(1+\frac{\gamma-1}{2} M_{N} \Delta \theta(x, t)\right)^{\frac{2 \gamma}{\gamma-1}}-1\right\}
$$

When using this approach, it is assumed that the body has a sharp leading edge with an attached shock.

\section{Unsteady Newtonian Impact Theory}

The distance between the shock and surface of a vehicle diminishes as the Mach number of the flow increases $[1,30]$. For a fluid moving over relatively simple shapes at a sufficiently high Mach number (i.e., $M_{\infty} \gg 1$ ), it can be assumed that the speed and direction of the gas particles in the freestream remain unchanged until they strike the windward surface of the vehicle $[1,16,30]$. Using this assumption and ignoring intermolecular forces, the normal component of momentum of the impinging fluid particle is lost, while the tangential component of momentum is conserved $[1,16,30]$. Consider a surface, shown in Fig. $\underline{5}$, which is exposed to hypersonic flow.

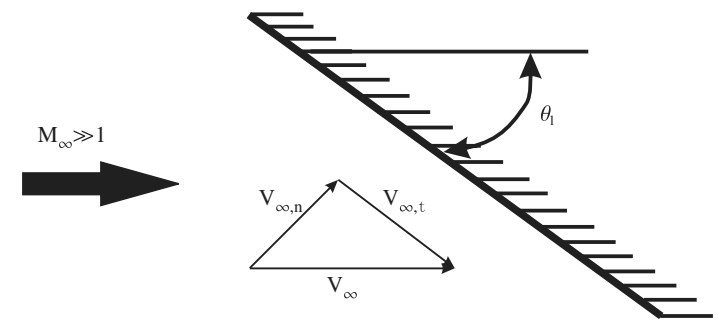

Fig. 5 Newtonian flow model [16].

Using this model, the change in momentum for a constant-area stream tube normal to the surface is given by [30]

$$
\left(\rho_{\infty} \mathbf{U}_{\infty} \cdot \hat{\mathbf{n}}\right)\left(\mathbf{U}_{\infty}-\mathbf{U}_{w}\right)=\left(p_{w}-p_{\infty}\right) \hat{\mathbf{n}}
$$

where $p_{\infty}, \rho_{\infty}$, and $\mathbf{U}_{\infty}$ are the freestream pressure, density, and velocity vector, respectively; $\mathbf{U}_{w}$ and $p_{w}$ are the velocity vector and pressure on the surface; and $\hat{n}$ denotes the unit vector along the outward normal to the surface. Since the normal component of momentum is zero at the body surface, this reduces to

$$
p_{w}-p_{\infty}=\rho_{\infty}\left(\mathbf{U}_{\infty} \cdot \hat{\mathbf{n}}\right)^{2}
$$

and therefore the pressure coefficient is given by

$$
C_{p}=2\left(\frac{\mathbf{U}_{\infty} \cdot \hat{\mathbf{n}}}{\left|\mathbf{U}_{\infty}\right|}\right)^{2}
$$

In Fig. 5, note that $\left|\mathbf{U}_{\infty}\right|=V_{\infty}$. Furthermore, for a surface at an inclination $\theta_{l}$ to the flow,

$$
\mathbf{U}_{\infty} \cdot \hat{\mathbf{n}}=-V_{\infty} \sin \theta_{l}
$$

Thus, the pressure coefficient using Newtonian impact theory is given by

$$
C_{p}=2 \sin ^{2} \theta_{l}
$$

Note that for

$$
\mathbf{U}_{\infty} \cdot \hat{\mathbf{n}} \geq 0
$$

the flow is in the aerodynamic shadow. In this region, $C_{p}$ is assumed to be zero.

Note that Eq. (37) represents a flow condition over a generic surface where $M_{\infty} \rightarrow \infty$ and $\gamma \rightarrow 1[\underline{1}, \underline{16}, \underline{30}]$. This corresponds to a shock wave outlining the body surface and an infinitesimal shock layer between the body and the shock. To achieve better accuracy at lower Mach numbers, Eq. (37) is typically replaced by

$$
C_{p}=\left(C_{p}\right)_{\max } \sin ^{2} \theta_{l}
$$

where

$$
\left(C_{p}\right)_{\max }=\frac{2}{\gamma M_{\infty}^{2}}\left(\left(\frac{(\gamma+1)^{2} M_{\infty}^{2}}{4 \gamma M_{\infty}^{2}-2(\gamma-1)}\right)^{\frac{\gamma}{(\gamma-1)}}\left(\frac{1-\gamma+2 \gamma M_{\infty}^{2}}{\gamma+1}\right)-1\right)
$$

which corresponds to the pressure coefficient at the stagnation point of the body. The expression in Eq. (39), known as modified Newtonian impact theory $[1,16]$, is the approach investigated here.

As before, the unsteady aerodynamic expression is obtained by replacing the steady inclination angle with the quasi-steady angle [28]:

$$
C_{p}(x, t)=\left(C_{p}\right)_{\max } \sin ^{2}\left\{\tan ^{-1}\left(\frac{v_{n}}{V_{\infty}}\right)\right\}
$$

As noted in [1], this theory is referred to as Newtonian impact theory, since it resembles a flow model derived by Sir Isaac Newton. Note that Newtonian impact aerodynamics is intended for high Mach 
number flows and/or for portions of the flow that have a large inclination to the surface of a body [27-29,41].

\section{E. Approximate Model for Viscous Effects Using Effective Shapes}

In hypersonic flow, inviscid-viscous interactions, where the boundary layer displaces the outer inviscid flow causing a body to appear thicker, become significant $[1,16,30]$. This apparent thickness influences both the surface pressure distribution and the vehicle aeroelastic stability $[31,32,34]$. Previous work [32] investigated a simple approximation for these effects in aeroelastic computations by adding a static boundary-layer displacement thickness to a lifting surface. The addition of the effective thickness improved piston theory correlations with experiments; however, in some cases it resulted in overly conservative flutter boundary predictions.

To further examine such an approach, two methods are considered here for computing the static boundary-layer displacement. The first uses semi-empirical, compressible flat-plate boundary-layer relations to modify the shape of airfoil sections and is considered because it was used previously in aeroelastic analysis [32]. The second approach uses steady pressure data generated from the solution of steady Navier-Stokes equations.

\section{Semi-Empirical Boundary-Layer Displacement Thickness Equations}

The semi-empirical relation used in [32] is given in Cox and Crabtree [45] as

$$
Z_{f p}(x)=\frac{\gamma-1}{\gamma+1}\left(0.664+1.73 \frac{T_{W}}{T_{0}}\right) M_{\infty}^{2} \sqrt{\frac{C_{w}}{R e_{x}}} x
$$

Equation (42) is based on the assumption of laminar flow with weak viscous interactions. This equation is modified by additional manipulations. First, it is assumed that $P r \approx 1$, and the adiabatic wall condition, i.e., $T_{W}=T_{\mathrm{AW}}$, is introduced:

$$
\frac{T_{W}}{T_{0}} \approx 1
$$

Next, the Chapman-Rubesin coefficient $C_{w}$ is computed from

$$
C_{w}=\frac{\mu_{w}}{\mu_{\infty}} \frac{T_{\infty}}{T_{W}}
$$

where $T_{W}$ is given by

$$
T_{W}=T_{\infty}\left(1+\frac{\gamma-1}{2} M_{\infty}^{2}\right)
$$

and $\mu_{w}$ is given by Sutherland's law: i.e.,

$$
\mu_{w}=1.458 \times 10^{-6} \frac{T_{W}^{1.5}}{T_{W}+110.4}
$$

Note that Eq. (46) assumes that $T_{W}$ is in units of Kelvin, resulting in $\mu_{w}$ that has units of $\mathrm{kg} /(\mathrm{m} \cdot \mathrm{s})$. Using Eqs. (42-46) in conjunction with freestream properties of the fluid and the position $x$ along the airfoil yields the approximate effective shape of the airfoil due to a viscous boundary layer: i.e.,

$$
Z_{\text {eff }}(x)=Z_{f p}(x)+Z_{\text {str }}(x)
$$

\section{Boundary-Layer Displacement Thickness Approximated from Steady-State CFD Flow Analysis}

The amount of viscous interaction between the outer inviscid flow and flow within the boundary layer can vary between strong and weak, depending on position along the surface of a body [1]. Furthermore, boundary layers in hypersonic flow are often characterized by both laminar and turbulent regions, with a specific transition point along the body [16]. Both of these issues degrade the accuracy of the effective shape given by Eq. (42) for the aerodynamic surface. The accuracy in calculating the displacement thickness can be improved, however, by using a CFD solution based on the steady Navier-Stokes equations. In such an approach, the effective shape correction is obtained from the steady pressure distribution by establishing a point-function relation between the pressure and the surface of the body. Since piston theory provides such a relation, it is a convenient choice for this approach.

The steady component of the piston theory pressure coefficient is obtained from Eq. (5) by neglecting all time dependent terms. For zero angle of attack, this is given by

$$
C_{p \mathrm{PT}}(x)=\frac{2}{M_{\infty}}\left\{\frac{\mathrm{d} Z_{\text {eff }}}{\mathrm{d} x}+\frac{(\gamma+1)}{4} M_{\infty}\left(\frac{\mathrm{d} Z_{\text {eff }}}{\mathrm{d} x}\right)^{2}+\frac{(\gamma+1)}{12} M_{\infty}^{2}\left(\frac{\mathrm{d} Z_{\text {eff }}}{\mathrm{d} x}\right)^{3}\right\}
$$

Equating the steady CFD Navier-Stokes coefficient of pressure with Eq. (48) yields a third-order polynomial for $\mathrm{d} Z_{\text {eff }} / \mathrm{d} x$,

$$
C_{p \mathrm{PT}}(x)-C_{p \mathrm{NS}}(x)=0
$$

Solving this equation at each surface grid point results in two complex roots and one real root that represents the slope of the effective airfoil shape at that grid point. The complete effective shape, $Z_{\text {eff }}(x)$, can then be obtained from this slope, $\mathrm{d} Z_{\text {eff }} / \mathrm{d} x$, by integrating along the length of the airfoil and assuming zero displacement thickness at the leading edge.

\section{F. Static Flow Approximation with Piston Theory Correction}

As previously discussed, despite the fact that hypersonic flows are quasi-steady, previous work [39] has demonstrated that the use of purely steady-state CFD flow analysis to model the unsteady aerodynamics compares less favorable to unsteady NS flow analysis than simpler approaches such as third-order piston theory. This indicates that unsteady effects cannot be ignored entirely when modeling the GAFs. It is hypothesized here that despite the importance of unsteady effects, the quasi-steady nature of the flow implies that they are of reduced importance compared to the steady flow effects. Thus, they may be reasonably approximated as a perturbation about a steady flow condition using simple aerodynamic models such as piston theory.

To construct a PT correction to the static CFD analysis, the aerodynamic pressure terms dependent on wash velocity must be identified. Substituting Eq. (1) into Eq. (5) yields the following equations:

$$
C_{p}(x, t)=C_{p, \text { vel }}(x, t)+C_{p, \mathrm{SS}}(x, t)+\bar{C}_{p}(x, t)
$$

where

$$
\begin{gathered}
C_{p, \text { vel }}(x, t)=\frac{2}{M_{\infty} V_{\infty}}\left(\frac{\partial Z}{\partial t}\right)+\frac{\gamma+1}{2 V_{\infty}^{2}}\left(\frac{\partial Z}{\partial t}\right)^{2} \\
+\frac{(\gamma+1) M_{\infty}}{6 V_{\infty}^{3}}\left(\frac{\partial Z}{\partial t}\right)^{3} \\
C_{p, \mathrm{SS}}(x, t)=\frac{2}{M_{\infty}}\left(\frac{\partial Z}{\partial x}\right)+\frac{\gamma+1}{2}\left(\frac{\partial Z}{\partial x}\right)^{2}+\frac{(\gamma+1) M_{\infty}}{6}\left(\frac{\partial Z}{\partial x}\right)^{3}
\end{gathered}
$$

$$
\begin{gathered}
\bar{C}_{p}(x, t)=\frac{\gamma+1}{V_{\infty}}\left(\frac{\partial Z}{\partial t}\right)\left(\frac{\partial Z}{\partial x}\right)+\frac{(\gamma+1) M_{\infty}}{2 V_{\infty}^{2}}\left(\frac{\partial Z}{\partial t}\right)^{2}\left(\frac{\partial Z}{\partial x}\right) \\
+\frac{(\gamma+1) M_{\infty}}{2 V_{\infty}}\left(\frac{\partial Z}{\partial t}\right)\left(\frac{\partial Z}{\partial x}\right)^{2}
\end{gathered}
$$

Equations (51) and (53) represents components of pressure due to aerodynamic damping, while Eq. (52) is the steady-state pressure contribution from piston theory, leading to aerodynamic stiffness terms. Note that Eq. (53), which represents the second- and thirdorder piston theory contributions to the wash-velocity terms, also 
depends on the surface inclination $(\partial Z / \partial x)$. For this approach, Eq. (52) is replaced with the steady-state pressure computed from a CFD Navier-Stokes flow analysis. This approach is denoted here as the $\mathrm{NS}_{\mathrm{SS}-\mathrm{PT}}$ method. Note that in order to increase computational efficiency and ease of implementation, the steady-state NS lift and moment coefficients were computed by constructing a kriging surrogate, as described in Appendix A.

\section{Aeroelastic Problem and Its Solution}

The quality of the approximate unsteady hypersonic aerodynamic models described in the previous sections are evaluated using the two-degree-of-freedom airfoil shown in Fig. 1. Two separate aeroelastic solutions are generated and compared: the first for the approximate aerodynamic models and the second implemented by CFL3D for the full-order CFD-based aeroelastic analysis.

\section{A. Aeroelastic Solution Using Approximate Unsteady Aerodynamics}

Assuming a linear system and no structural damping, the equations of motion for this simple system can be obtained using Lagrange's equations:

$$
m \ddot{h}+S_{\alpha} \ddot{\alpha}+K_{h} h=-L \quad S_{\alpha} \ddot{h}+I_{\alpha} \ddot{\alpha}+K_{\alpha} \alpha=M_{E A}
$$

where the sectional aerodynamic forces $L$ and $M_{E A}$ are calculated by integrating the unsteady aerodynamic pressure coefficient:

$$
\begin{gathered}
L=\int_{-b}^{b} q_{\infty} \Delta C_{p}(\dot{h}, \alpha, \dot{\alpha}) \mathrm{d} x \\
M_{E A}=-\int_{-b}^{b} q_{\infty}(x-b a) \Delta C_{p}(\dot{h}, \alpha, \dot{\alpha}) \mathrm{d} x
\end{gathered}
$$

The spatial integrations of pressure are carried out numerically using Gaussian quadrature of order 2, while the time integration is carried out numerically using the ODE45 solver in MATLAB®.

\section{B. Aeroelastic Solution Using Navier-Stokes Flow Analysis}

The NASA Langley CFL3D code [46,47], used previously by the authors $[34, \underline{42}, 48]$ to conduct studies on the hypersonic aeroelastic behavior of generic reusable launch vehicles and lifting surfaces, is also used in this study for CFD-based aeroelastic analysis. The code contains a Navier-Stokes solver, deforming mesh algorithm, and structural solver, enabling CFD-based aeroelastic analysis.

The aeroelastic approach underlying the CFL3D code is similar to that described in $[49,50]$. The equations are derived by assuming that the general motion $\overline{w_{d}}(x, y, z, t)$ of the structure is described by a finite modal series given by Eq. (57). The functions $\phi_{i}(x, y, z)$ represent the free-vibration modes of a structure:

$$
w_{d}(x, y, z, t)=\sum_{i=1}^{n_{m}} q_{i}(t) \phi_{i}(x, y, z)
$$

The aeroelastic equations of motion are obtained from Lagrange's equations, which yield

$$
\mathbf{M} \ddot{\mathbf{q}}+\mathbf{K q}=\mathbf{Q}(\mathbf{q}, \dot{\mathbf{q}}, \ddot{\mathbf{q}}), \quad \mathbf{q}^{T}=\left[\begin{array}{llll}
q_{1} & q_{2} & \ldots & q_{n_{m}}
\end{array}\right]
$$

where the elements of the generalized force vector are given by

$$
Q_{i}=\int_{S} q_{\infty} \phi_{i} \Delta C_{p}(\mathbf{q}, \dot{\mathbf{q}}, \ddot{\mathbf{q}}) \mathrm{d} S
$$

The aeroelastic equations are written in terms of a linear state-space equation (using a state vector of the form $\left[\begin{array}{llllll}\ldots & \dot{q}_{i-1} & q_{i} & \dot{q}_{i} & q_{i+1} & \ldots\end{array}\right]^{T}$ ), and a modified state-transitionmatrix integrator is used to march the coupled fluid-structural system forward in time. This process yields a time history of the modal displacements, modal velocities, and generalized forces.

\section{Flutter Boundary Identification}

The flutter conditions at a given altitude are determined from a set of aeroelastic transients computed at several Mach numbers and corresponding dynamic pressures. The frequency and damping characteristics of each transient response, as a function of the structural configuration and operating conditions used in Eq. (54), are determined using autoregressive moving-average (ARMA) system identification [48].

The approach is based on a single-input/single-output deterministic ARMA model of the aeroelastic system, with $2 n_{m}$ autoregressive (AR) and one moving-average (MA) coefficients [51]. The model has the following form:

$$
w_{d}^{k}+\sum_{i=1}^{2 n_{m}} a_{i} w_{d}^{k-i}=b_{1} \delta^{k-1}
$$

where $2 n_{m}$ AR coefficients are used to determine the aeroelastic system damping and frequencies, and one MA coefficient is sufficient for identifying an aeroelastic static offset [51]. To identify the damping and frequency, the transient aeroelastic response is represented by the following AR model:

$$
w_{d}^{k}+\sum_{i=1}^{2 n_{m}} a_{i} w_{d}^{k-i}=0
$$

This can be written in state-space form as

$$
\left\{X_{p}\right\}^{k+1}=\left\{\mathbf{A}_{\mathbf{p}}\right\}\left\{X_{p}\right\}^{k} \quad w_{d}^{k}=\left\{\mathbf{C}_{\mathbf{p}}\right\}\left\{X_{p}\right\}^{k}
$$

where

$$
\left\{\mathbf{A}_{\mathbf{p}}\right\}=\left[\begin{array}{ccccc}
-a_{1} & 1 & 0 & \cdots & 0 \\
-a_{2} & 0 & 1 & \cdots & 0 \\
\vdots & \vdots & \vdots & \ddots & \vdots \\
-a_{2 n_{m}-1} & 0 & 0 & \cdots & 1 \\
-a_{2 n_{m}} & 0 & 0 & \cdots & 0
\end{array}\right]
$$

and

$$
\left\{\mathbf{C}_{\mathbf{p}}\right\}=\left[\begin{array}{lllll}
1 & 0 & 0 & \cdots & 0
\end{array}\right]
$$

The state vector $\left\{X_{p}\right\}^{k}$ is defined as

$$
\left\{X_{p}\right\}^{k} \equiv\left\{\begin{array}{c}
w_{d}^{k} \\
h_{1}(k) \\
\vdots \\
h_{2 n_{m}-1}(k)
\end{array}\right\}
$$

with

$$
\begin{gathered}
w_{d}^{k}=-a_{1} w_{d}^{k-1}+h_{1}(k-1) \\
h_{1}(k)=-a_{2} w_{d}^{k-1}+h_{2}(k-1) \\
\vdots \\
h_{2 n_{m}-2}(k)=-a_{2 n_{m}-1} w_{d}^{k-1}+h_{2 n_{m}-1}(k-1) \\
h_{2 n_{m}-1}(k)=-a_{2 n_{m}} w_{d}^{k-1}
\end{gathered}
$$

The state-space description of the AR model in Eq. (62) is in observer form and is completely observable. The aeroelastic system damping and frequencies are determined from the eigenvalues of the estimated matrix [1],$\left\{\mathbf{A}_{\mathbf{p}}\right\}$, given in Eq. (3). These can be written as

$$
\Lambda_{j}=r_{j}+i s_{j} \quad \Lambda_{j+n_{m}}=r_{j}-i s_{j}
$$

where $j=1,2, \ldots, n_{m}$. Note that the AR model is in the discretetime domain. The aeroelastic modal damping and frequencies in the continuous-time domain are given by [51] 


$$
\zeta_{j}=\frac{1}{2 T_{e}} \log _{e}\left(r_{j}^{2}+s_{j}^{2}\right) \quad \omega_{j}=\frac{1}{T_{e}} \tan ^{-1} \frac{s_{j}}{r_{j}}
$$

In this study, the AR coefficients are determined from the aeroelastic responses using the subroutine AR from the system-identification toolbox in MATLAB. The sampling times used to calculate the AR coefficients from the response data are

$$
T_{e}=\frac{\pi}{2\left(\omega_{n}\right)_{\max }}
$$

where $\left(\omega_{n}\right)_{\max }$ is the maximum system natural frequency in radians/ second.

Recently, a flutter parameter for discrete-time systems has been derived using the AR coefficients of an ARMA model [52]. For binary flutter problems, such as that considered here, the flutter parameter is linear $[48,52]$ with dynamic pressure for $0.4 q_{f}<$ $q_{\infty}<1.0 q_{f}$. The advantage of this parameter is that it limits the number of subcritical responses required to locate the flutter boundary to two.

The flutter parameter is given by [52]

$$
F_{Z}=\frac{F^{-}\left(2 n_{m}-1\right)}{F^{-}\left(2 n_{m}-3\right)^{2}}
$$

where

$$
F^{-}(j)=\operatorname{det}\left(X_{j}-Y_{j}\right)
$$

and

$$
\left\{X_{j}\right\}=\left[\begin{array}{ccc}
\bar{A}_{2 n_{m}} & \cdots & \bar{A}_{2 n_{m}-j+1} \\
0 & \ddots & \vdots \\
0 & 0 & \bar{A}_{2 n_{m}}
\end{array}\right], \quad\left\{Y_{j}\right\}=\left[\begin{array}{ccc}
\bar{A}_{j-1} & \cdots & \bar{A}_{0} \\
\vdots & \ddots & 0 \\
\bar{A}_{0} & 0 & 0
\end{array}\right]
$$

and

$$
\left\{\begin{array}{c}
\bar{A}_{2 n_{m}} \\
\bar{A}_{2 n_{m}-1} \\
\vdots \\
\bar{A}_{0}
\end{array}\right\}=\left\{\begin{array}{c}
1 \\
a_{1} \\
\vdots \\
a_{2 n_{m}}
\end{array}\right\}
$$

This approach is implemented by computing the flutter parameter at the same altitude and configuration from aeroelastic transients for two different Mach numbers. The flutter dynamic pressure, and subsequently the flutter Mach number, is computed using a linear extrapolation from these two points. If the predicted flutter dynamic pressure is not within $40 \%$ of the dynamic pressures used to compute the aeroelastic transients, the process is repeated at an increased Mach number.

\section{Results}

An assessment of the different aerodynamic theories over different ranges of Mach numbers is important in order to identify ranges of applicability for hypersonic aeroelasticity. Thus, aeroelastic results generated using the various unsteady aerodynamic models are compared to those computed using Navier-Stokes aerodynamics in terms of flutter boundaries for $5.0<M_{\infty}<35$.

An important parameter for comparison in the hypersonic flow regime is the hypersonic similarity parameter, which is the product of the freestream Mach number and surface inclination of a body. This parameter is useful because it describes similarity for different flow/ body combinations [1]. For the typical section, hypersonic similarity is given by $M \tau$, where $\tau$ is the thickness ratio of the airfoil.

Note that in order in order to generate flutter over the range $5.0<M_{\infty}<35$ for the double-wedge airfoil configuration discussed below, relatively low altitudes $(40,000 \mathrm{ft}-60,000 \mathrm{ft})$ are required. Clearly hypersonic vehicles cannot operate in such conditions. However, this is a common issue in the computation of flutter
Table 1 Parameters describing the double-wedge airfoil

\begin{tabular}{lc}
\hline \hline Parameter, unit & Value \\
\hline$c, \mathrm{~m}$ & 2.35 \\
$\tau$ & 0.0336 \\
$m, \mathrm{~kg} / \mathrm{m}$ & 94.2 \\
$r_{\alpha}$ & 0.484 \\
$\omega_{h}, \mathrm{~Hz}$ & 13.4 \\
$\omega_{\alpha}, \mathrm{Hz}$ & 37.6 \\
$x_{\alpha}$ & 0.2 \\
\hline \hline
\end{tabular}

Table 2 Mass ratio and Reynolds number of the typical section at various altitudes

\begin{tabular}{lcc}
\hline \hline Altitude, $\mathrm{ft}$ & $\mu_{m}$ & $R e$ \\
\hline 40,000 & 69.87 & $2.3 \times 10^{8}$ \\
60,000 & 179.86 & $1.8 \times 10^{8}$ \\
\hline \hline
\end{tabular}

boundaries for representative hypersonic structural configurations when aerodynamic heating is neglected [53]. These altitudes are acceptable for the present study, since the scope is limited to assessing prediction tools for the GAFs at typical hypersonic Mach numbers. Studies that seek to compute realistic flutter boundaries of hypersonic configurations must incorporate aerodynamic heating effects $[29, \underline{34}, \underline{54}]$.

\section{A. Computational Model for the Double-Wedge Typical Section}

The parameters describing the double-wedge typical section are listed in Table 1 . The mass ratios and Reynolds numbers for the airfoil at the altitudes considered are listed in Table 2. These parameters were selected based on the $75 \%$ span location of the Lockheed F-104 wing. This configuration was chosen because it resembles low-aspect-ratio control surfaces on proposed hypersonic vehicles and also because data on its geometric and structural properties are readily available [34]. The CFD domain, shown in Fig. 6 , is a $2 \times 705 \times 65 C$-grid with 705 points around the airfoil and its wake (577 points on the airfoil surface), one point extending spanwise one unit length to close the control volume, and 65 points extending radially outward from the surface. This grid configuration and density was selected based on a mesh refinement study in [34] that demonstrated convergence of lift and moment coefficients to within 5\% and average $y^{+}$values for the first grid point off the surface to less than 2.5. Computational inputs for the CFL3D flow analysis are listed in Table 3.

\section{B. Flutter Boundaries for the Double-Wedge Typical Section}

The results presented in this section were obtained for the typical section shown in Fig. 1. First, results generated using the classical approximate aerodynamic theories (i.e., PT, VD, SE, and NI) are compared to the NS results. Next, a similar comparison is made between the flutter boundaries computed using effective shape corrections and NS aerodynamics. Finally, flutter boundaries computed using the LPT and $\mathrm{NS}_{\mathrm{SS}-\mathrm{PT}}$ methods are compared to both

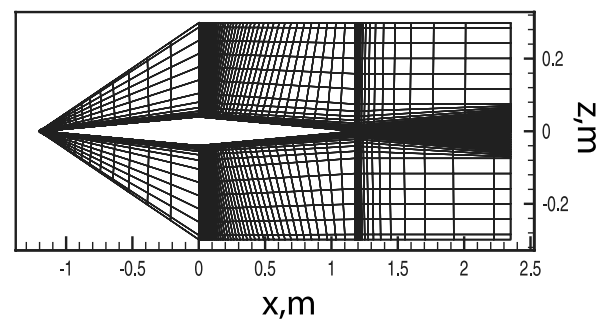

Fig. 6 Computational domain of the double-wedge airfoil. 
Table 3 CFL3D parameters for 2-D Navier-Stokes aeroelastic calculations

\begin{tabular}{lc}
\hline \hline Turbulence model & $\begin{array}{c}\text { Spalart-Allmaras } \\
\text { (no laminar regions) }\end{array}$ \\
\hline No. subiterations & 30 \\
CFL $_{\tau}$ & 5.0 \\
$\Delta t, \mathrm{~s}$ & $0.25 \mathrm{e}-3$ \\
No. of time steps & 250 \\
No. of cells & $0.46 \mathrm{e} 5$ \\
No. processors & 6 \\
Computational time, a min & 17 \\
\hline \hline
\end{tabular}

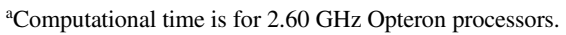

results generated from classical approximations and NS aerodynamics.

\section{Flutter Boundaries Obtained Using Classical Unsteady Hypersonic} Aerodynamic Theories

The flutter boundaries of the typical section computed using the classical approximate unsteady aerodynamic models, as well as from the full-order unsteady Navier-Stokes equations, are shown in Fig. 7. All results were generated from a zero-angle-of-attack aeroelastic steady-state condition. Note that second-order piston theory was excluded because it resulted in nearly equivalent flutter boundaries to that predicted using Van Dyke's second-order theory.

It is evident that, with the exceptions of the Newtonian impact and first-order piston theory flutter boundaries, the agreement is good to excellent for a wide range of Mach numbers $\left(8.0<M_{\infty}<30.0\right)$ and hypersonic similarity values $\left(0.25<M_{\infty} \tau<1.0\right)$. At an altitude of $40,000 \mathrm{ft}$, second- and third-order PT, VD, and SE all predict similar flutter boundaries to the NS result, even for the high flutter Mach

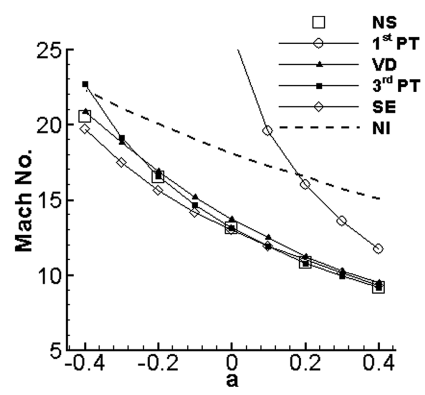

a) $40,000 \mathrm{ft}$

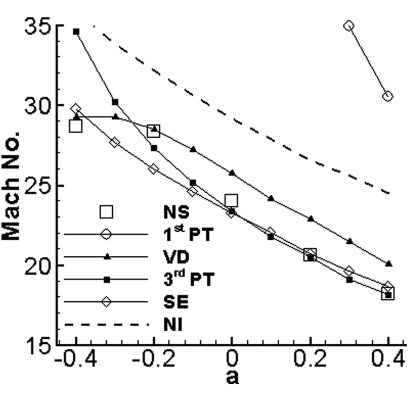

b) $60,000 \mathrm{ft}$
Fig. 7 Variation in the flutter Mach number of a double-wedge typical section as a function of elastic-axis offset parameter $a$.

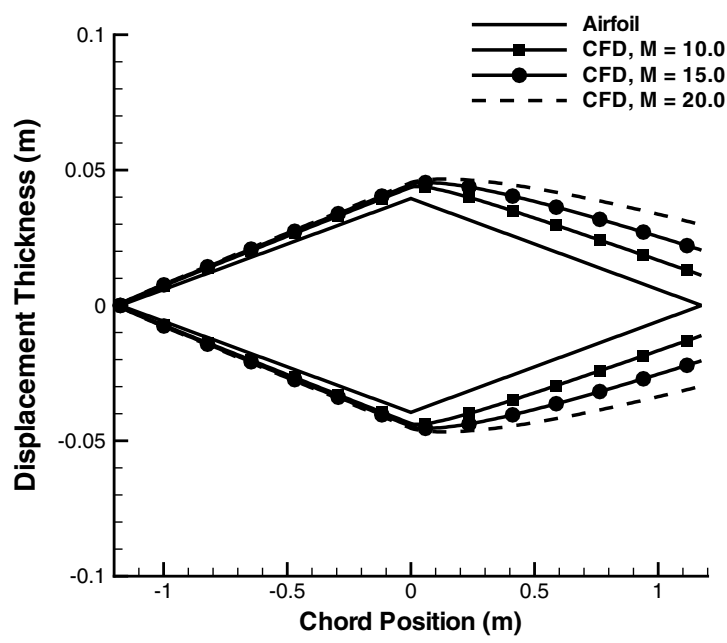

a) 40,000 feet

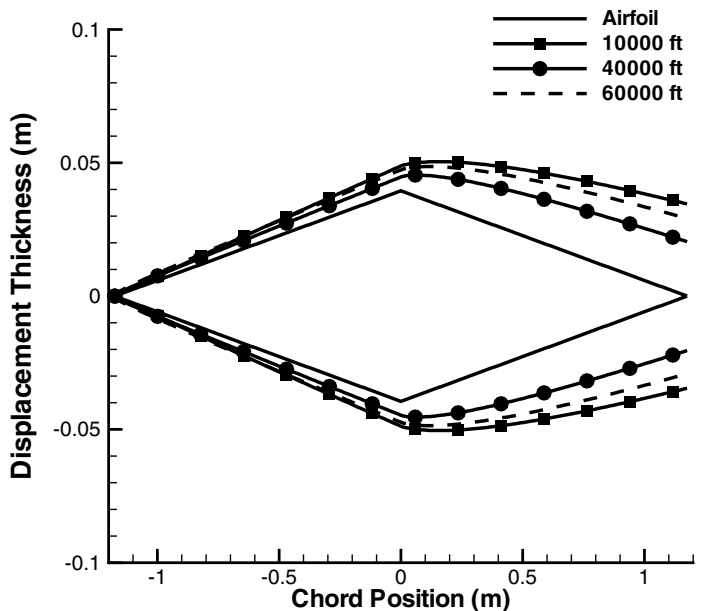

Fig. 9 Effective shapes generated using steady CFD pressure data, $M_{\infty}=\mathbf{1 5 . 0}$.

numbers that result from placing the elastic axis ahead of midchord. However, both NI and first-order PT overpredict the NS flutter boundary for the entire range of cases considered. Increasing the altitude to $60,000 \mathrm{ft}$ produces higher flutter Mach numbers and corresponding increases in differences between the flutter boundaries; however, agreement generally remains reasonable for all but the NI and first-order PT predictions.

Several conclusions can be drawn from these results. First, the divergence in flutter boundary prediction between first-order PT and the remaining aerodynamic models indicates that airfoil thickness, which is a second-order effect, is quite important in the hypersonic regime. Also, for the typical section, reasonable accuracy in predictions can be expected for second- and third-order PT, VD, and $\mathrm{SE}$ as long as $M_{\infty} \tau<1.0$. However, NI theory, which is preferred for blunt bodies at high Mach numbers, is not appropriate for such values of $M_{\infty} \tau$. Finally, it is clear that for this simple configuration and operating conditions, the effect of viscosity is negligible on the flutter boundary.

\section{Flutter Boundaries Using Effective Shape Corrections}

The apparent minimal impact of viscosity on the flutter boundary, and the use of effective shapes in previous hypersonic flutter analysis [32] motivates further study here. One explanation may be that the displacement thickness of the boundary layer is too small to impact aeroelastic stability. An alternative explanation may be that the additional dissipation due to viscosity counteracts the drop in stability associated with increased apparent thickness. Regardless, additional

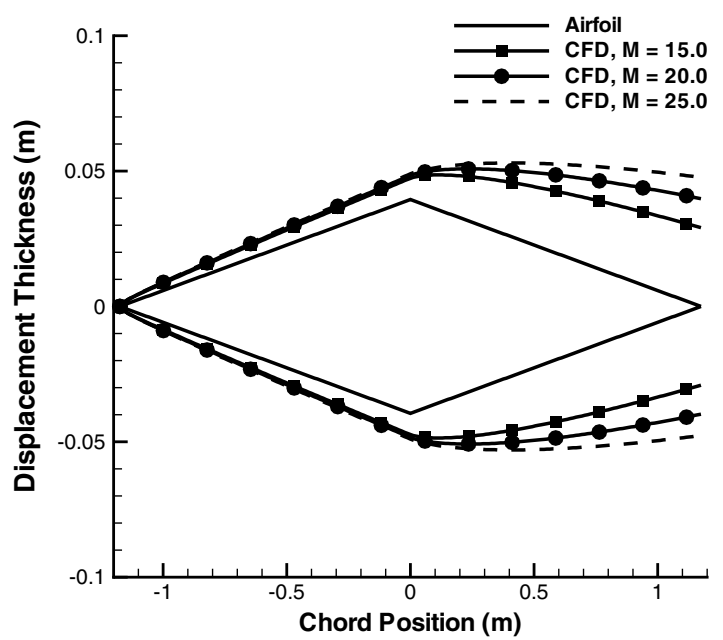

b) 60,000 feet

Fig. 8 Effective shapes generated using steady CFD pressure data at $40,000 \mathrm{ft}$ and $60,000 \mathrm{ft}$. 


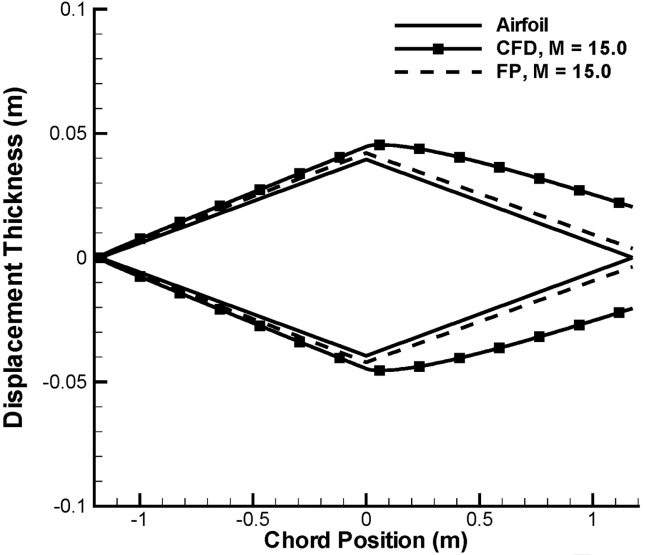

a) 40,000 feet, $\operatorname{Re}=2: 3 \times 10^{8}$

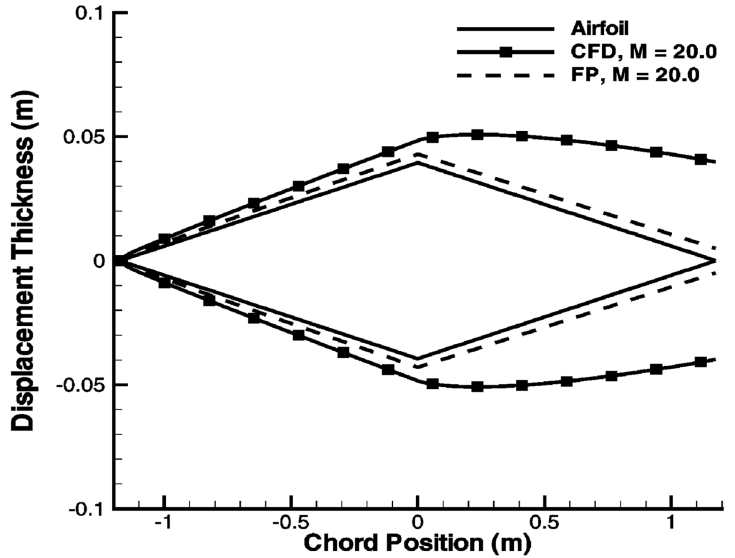

b) 60,000 feet, $\operatorname{Re}=1: 8 \times 10^{8}$

Fig. 10 Comparison of effective shapes generated using both a laminar FP approximation and steady CFD pressure data.

insight can be gained into the role of viscosity in hypersonic aeroelastic analysis by examining boundary-layer displacement thicknesses in hypersonic flow and by computing flutter boundaries using inviscid aerodynamics augmented with effective shape corrections.

Figures $\underline{8}-10$ depict effective shapes for the typical section, at various operating conditions, generated using both steady CFD Navier-Stokes pressure distributions and the laminar flat-plate (FP) boundary-layer relation given in Eq. (42). Note that the CFD-based effective shape was computed by assuming a turbulent boundary during the CFD flow analysis. Several observations on the influence of the boundary layer can be made. First, it is evident from Fig. 8 that increasing the Mach number increases the thickness of the effective shape at each of the altitudes considered. However, it is apparent from Fig. 9 that the thickness of the boundary layer, at a given Mach number, does not monotonically change with increasing altitude. It is also clear from Fig. 10 that the laminar flat-plate relation, given in Eq. (42), results in a significantly smaller effective shape over the aft portion of the airfoil.

Flutter boundaries of the typical section were computed using third-order PT with the flat-plate and CFD effective shape corrections. These boundaries are compared with that predicted using unsteady Navier-Stokes aerodynamics in Fig. 11. For the lower flutter Mach numbers at $40,000 \mathrm{ft}$, the addition of the effective shapes does not significantly alter the flutter boundary of the typical section. For the higher flutter Mach numbers, where presumably viscous displacement effects are more pronounced, the flutter boundary computed using the CFD-based effective shape is noticeably offset from the NS result. Furthermore, comparison of Figs. $\underline{7}$ and 11 illustrates that the addition of the CFD-based effective shape to thirdorder PT produces an overly conservative prediction where thirdorder PT originally matched the NS flutter boundary and provided no improvement at the worst-case, $60,000 \mathrm{ft}, a=-0.4$ flutter point. In contrast, the laminar flat-plate effective shape improved the piston theory correlation with the NS flutter boundary for all elastic-axis locations and both altitudes, despite the invalid assumption of a laminar boundary layer. These results suggest that the use of an effective shape correction may not be a reliable means for incorporating viscous effects.

\section{Flutter Boundaries Using Hybrid CFD/Piston Theory Approaches}

For computation of the LPT flutter boundaries, only the first-order terms from Eq. (9) are retained. This enables investigation into the importance of flow nonlinearities due to static flow effects through comparison of flutter results generated using first-order LPT, classical first-order PT, and unsteady Navier-Stokes aerodynamics. Also note that the local flow quantities are computed using a steadystate Euler CFD flow analysis. In hypersonic flow, Navier-Stokes aerodynamics are preferred due to the potential importance of viscous effects on the surface pressure [1] . However, the identification
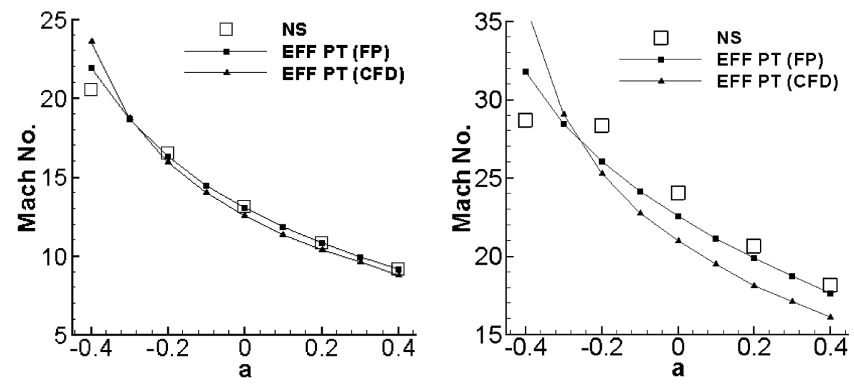

a) 40,000 feet

b) 60,000 feet

Fig. 11 Variation in the flutter Mach number, as a function of elasticaxis offset parameter $a$, computed using third-order piston theory with effective shape corrections and Navier-Stokes aerodynamics.

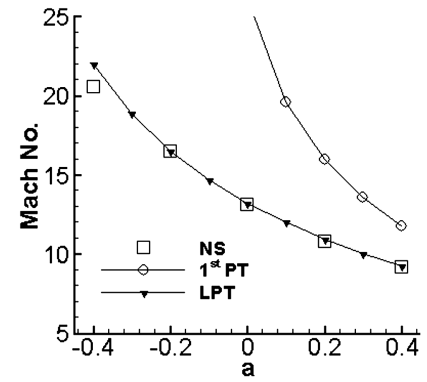

a) 40,000 feet

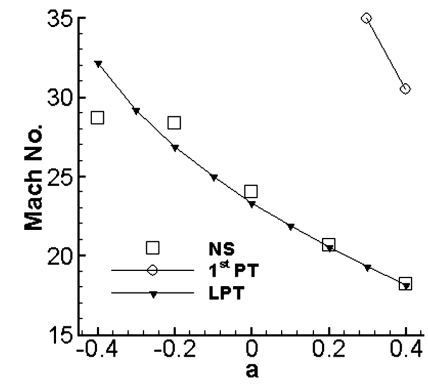

b) 60,000 feet
Fig. 12 Variation in the flutter Mach number, as a function of elasticaxis offset parameter $a$, computed using first-order piston theory (first PT), local piston theory (LPT), and unsteady Navier-Stokes aerodynamics (NS).

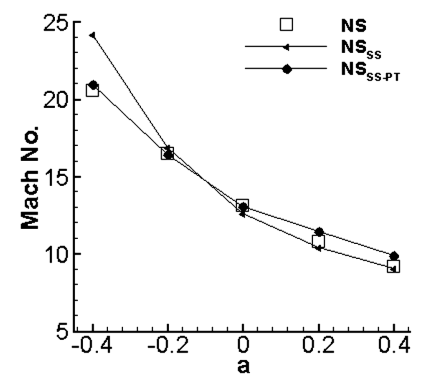

a) 40,000 feet

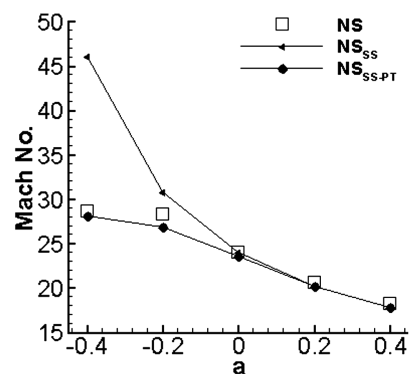

b) 60,000 feet
Fig. 13 Variation in the flutter Mach number, as a function of elasticaxis offset parameter $a$, computed using steady-state Navier-Stokes aerodynamics $\left(\mathrm{NS}_{\mathrm{SS}}\right)$, piston-theory-corrected steady-state $\mathrm{NS}$ aerodynamics $\left(\mathrm{NS}_{\mathrm{SS}-\mathrm{PT}}\right)$, and unsteady Navier-Stokes aerodynamics (NS). 
Table 4 Error metrics (in percent) for the flutter Mach number of a double-wedge typical section for several different aerodynamic modeling approaches relative to a CFD Navier-Stokes prediction

\begin{tabular}{lcrrrrrrc}
\hline \hline & Third PT & VD & \multicolumn{1}{c}{ SE } & LPT & NS $_{\text {SS-PT }}$ & NS $_{\text {SS }}$ & EFF (FP) & EFF (CFD) \\
\hline NRMSE (40,000 ft) & 5.0 & 2.1 & 2.9 & 3.5 & 2.3 & 8.6 & 3.1 & 7.4 \\
NRMSE (60,000 ft) & 14.0 & 7.8 & 6.3 & 9.3 & 4.0 & 45.3 & 9.8 & 23.7 \\
NRMSE (all) & 10.5 & 5.7 & 4.9 & 7.0 & 3.3 & 30.9 & 7.2 & 16.8 \\
$L_{\infty}$ & 30.6 & 11.2 & 12.0 & 19.3 & 7.4 & 89.6 & 16.0 & 38.5 \\
\hline \hline
\end{tabular}

of the local Mach number is difficult in a Navier-Stokes analysis, since it must be computed at the edge of the boundary layer, which is not known a priori.

The flutter boundaries computed using LPT are compared to the first-order PT and the unsteady NS flutter boundaries in Fig. 12. It is clear that while first-order PT quickly diverges, the LPT flutter boundary nearly matches the NS prediction for all but the $a=-0.4$ elastic-axis location at $60,000 \mathrm{ft}$. Thus, flow nonlinearities due to shocks and expansion fans over the steady airfoil are incorporated into the LPT approach. The agreement between the NS and LPT predictions in conjunction with the divergence of the standard firstorder PT prediction demonstrates the potential to capture primary flow nonlinearities using a static flow analysis.

The flutter boundaries computed using the $\mathrm{NS}_{\mathrm{SS}-\mathrm{PT}}$ approach are compared to those predicted using unsteady NS results in Fig. 13. In addition, the flutter boundaries predicted using a purely steady-state NS flow analysis $\left(\mathrm{NS}_{\mathrm{SS}}\right)$ are included, which are only a function of instantaneous surface inclination. The $\mathrm{NS}_{\mathrm{SS}-\mathrm{PT}}$ flutter boundaries are in excellent agreement with the unsteady NS prediction for all elastic-axis offset locations and operating altitudes. In contrast, the $\mathrm{NS}_{\mathrm{SS}}$ flutter boundaries are in excellent agreement with the unsteady NS prediction for elastic-axis locations aft of midchord but are in poor agreement as the elastic axis is moved ahead of midchord. Furthermore, for elastic-axis locations ahead of midchord, the differences in the flutter boundary increases with Mach number. These results further support the hypothesis that the GAFs are primarily dependent on steady flow effects. However, unsteady terms should clearly not be neglected entirely.

Note that only first- and second-order PT aerodynamic damping terms from Eqs. (51) and (53) were used for the $\mathrm{NS}_{\mathrm{SS}-\mathrm{PT}}$ method, since these yielded the best correlation with the unsteady NS predictions. Specifically, the inclusion of second-order terms resulted in a flattening of the flutter boundary for $a<-0.2$ at $60,000 \mathrm{ft}$, similar to the NS flutter boundary, while the first order only or the addition of the third-order terms resulted in overpredictions of the flutter Mach number. Note that this discrepancy is also evident when comparing VD, third-order piston theory, and LPT results in Figs. $7 \mathrm{~b}$ and $12 \mathrm{~b}$.

\section{Error Metrics for the Predicted Flutter Boundaries}

The correlation of the approximate methods with the NS flutter boundary predictions are quantified in Table 4 using the normalized root-mean-square error (NRMSE) and normalized $L_{\infty}$ error metrics defined in Eqs. (74) and (75):

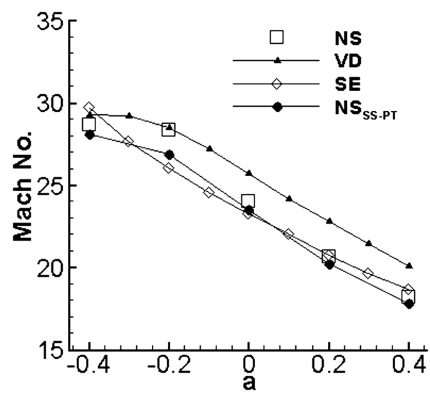

Fig. 14 Variation in the flutter Mach number, as a function of elasticaxis offset parameter $a$, computed using $\mathrm{VD}, \mathrm{SE}$, and $\mathrm{NS}_{\mathrm{SS}-\mathrm{PT}}$, and unsteady NS aerodynamics; $60,000 \mathrm{ft}$.

$$
\begin{aligned}
\mathrm{NRMSE} & =\frac{\sqrt{\sum_{n=1}^{N} \frac{1}{N}\left(\mathrm{ROM}_{n}-\text { Full }_{n}\right)^{2}}}{\operatorname{Max}(\text { Full })-\operatorname{Min}(\text { Full })} \\
L_{\infty} & =\frac{\operatorname{Max}(\mid \mathrm{ROM}-\text { Full } \mid)}{\operatorname{Max}(\text { Full })-\operatorname{Min}(\text { Full })}
\end{aligned}
$$

Note that the errors of first-order PT and NI were not included, since these approaches were clearly not accurate for the present case. Furthermore, second-order PT is also not listed, since it produces practically equivalent flutter boundary predictions.

As noted previously, each of the approaches are in close agreement with the NS predictions at $40,000 \mathrm{ft}$, with larger errors at the higher Mach numbers at $60,000 \mathrm{ft}$. It is interesting that the VD flutter boundaries are in better agreement with the NS results than thirdorder PT. This is primarily due to the second-order models prediction of a flattening of the flutter Mach number, for $a<-0.2$ at $60,000 \mathrm{ft}$, that follows the NS analysis. Note that in the derivation of piston theory, Lighthill [22] acknowledges uncertainty in the inclusion of the third-order binomial expansion term that yields third-order piston theory. This is an interesting result that warrants further study on more realistic configurations, so as to further examine the relative merits of second-order versus third-order piston theory.

A second interesting result is the outperformance of the laminar flat-plate effective shape correction compared to the CFD-based correction. Comparing the errors of these two methods with the error for standalone third-order piston theory demonstrates that the laminar flat-plate correction yields a noticeable reduction in error, while the addition of a CFD-based correction results in an increase in error. However, as noted above, the improvement of the laminar flatplate correction is dubious, since the NS predictions are based on an assumption of fully turbulent flow. These error metrics further emphasize that the effect of viscosity on the aeroelastic behavior cannot be reliably captured using effective shape corrections.

Based on the errors listed in Table 4, the best approaches relative to unsteady NS predictions are VD/second-order PT, SE, and $\mathrm{NS}_{\mathrm{SS}-\mathrm{PT}}$. Each of these have an NRMSE error within $6 \%$ over all the cases considered $\left(8.0<M_{\infty}<30.0,0.25<M_{\infty} \tau<1.0\right)$, and an $L_{\infty}$ norm within $12 \%$. For further comparison, the $60,000 \mathrm{ft}$ flutter boundaries from these three approaches and unsteady NS aerodynamics are plotted in Fig. 14. It is clear that while the average and maximum errors of these three approaches are similar, the VD and $\mathrm{NS}_{\mathrm{SS}-\mathrm{PT}}$ most closely follow the unsteady NS flutter boundary trends with elastic-axis position. Furthermore, for the majority of the boundary, the VD prediction is unconservative compared to the $\mathrm{NS}_{\mathrm{SS}-\mathrm{PT}}$ and SE predictions. Thus, for this configuration, the $\mathrm{NS}_{\mathrm{SS}-\mathrm{PT}}$ approach is noticeably more accurate compared to all the modeling approaches considered.

\section{Conclusions}

This paper examines the performance of various approximations to the unsteady aerodynamics in hypersonic flow by computing the aeroelastic stability boundaries for a typical section. Despite the simplicity of the configuration studied, several noteworthy conclusions can be drawn from the results. First, the use of first-order piston theory aerodynamics in hypersonic flow results in highly unconservative flutter boundary predictions. In contrast, for hypersonic similarity values up to 1.0: Van Dyke's second-order theory, secondorder piston theory, unsteady shock-expansion theory, and a hybrid 
steady-state Navier-Stokes/piston theory method produce flutter boundaries within an average difference of $6 \%$ and maximum difference of $12 \%$, relative to unsteady Navier-Stokes predictions. The good correlation with the unsteady Navier-Stokes flutter boundary and the inviscid approximate theories indicates that the impact of viscosity on the flutter boundaries of a thin typical-section is negligible. Finally, the high error of first-order piston theory contrasted with the good-to-excellent correlation of the first-order local piston theory indicates that dynamic aeroelastic stability is strongly influenced by thickness effects and that for the typical section, the effect of thickness on the generalized aerodynamic forces can be effectively captured using steady-state flow analysis. The merit of using steady-state flow analysis to generate flutter boundary predictions is further supported by the excellent agreement of the hybrid Navier-Stokes/piston theory method. This implies that steady-state CFD flow analysis may be a means to incorporate complex flow effects at significantly reduced computation times compared to time-accurate analysis. However, more rigorous test cases and thorough investigation are needed to fully assess such an approach for general use.

\section{Appendix A: Surrogate Modeling of Steady-State Hypersonic Aerodynamics}

To avoid the significant expense of repeated CFD computations, Navier-Stokes based kriging surrogates [55-60] were used in conjunction with the $\mathrm{NS}_{\mathrm{SS}-\mathrm{PT}}$ method. Kriging is an interpolation method useful for replacing expensive computer models with computationally efficient approximations of nonlinear functions $[56,61,62]$. Typical prediction times are on the order of a fraction of a second. Kriging interpolation was used in this study because this method is well suited to approximating nonlinear functions and does not require a priori assumptions on the form of the full-order function that is to be approximated.

A kriging surrogate is generated from training data, or snapshots, of the full-order simulation of the computer model. A kriging approximation of the function of interest is characterized by local deviations $\mathbf{C}(\mathbf{x})$ from a global approximation $\mathbf{R}(\mathbf{x})$, as defined in Eq. (스) [55]:

$$
\mathbf{y}(\mathbf{x})=\mathbf{R}(\mathbf{x})+\mathbf{C}(\mathbf{x})
$$

Typically, $\mathbf{R}(\mathbf{x})$ is a polynomial regression function, which is assumed to be either constant, linear, or quadratic, and the constants of the polynomials are generally determined in a least-squares sense. The quantity $\mathbf{C}(\mathbf{x})$ provides the local deviations by means of a correlation function, defined by the user. For this study, the kriging surrogate was constructed using the DACE [58] (Design and Analysis of Computer Experiments) toolbox in MATLAB. This toolbox allows one to efficiently evaluate constant, linear, and quadratic regression functions in addition to several different correlation functions (e.g., Gaussian and cubic spline). Both Gaussian $[\underline{55}, \underline{56}, \underline{58}, 59]$ and cubic spline [58] correlation functions were investigated.

The NS-based surrogate was constructed to replace $C_{p, \mathrm{SS}}(x, t)$ in Eq. (52). Three parameters were used to generate the surrogate for the double-wedge typical section: namely, 1) freestream Mach number, 2) pitch angle $\alpha$, and 3 ) altitude. The ranges considered for these three parameters are listed in Table A1. The surrogate was constructed from 200 full-order Navier-Stokes CFD sample points, selected using LHSDESIGN in MATLAB, with the criterion to maximize the minimum distance between sample points over five-hundred iterations.

Table A1 Range of parameters used to construct the steady Navier-Stokes surrogate.

\begin{tabular}{ccc}
\hline \hline 5.0 & $\leq M_{\infty} \leq$ & 35.0 \\
$-2.0^{\circ}$ & $\leq \alpha \leq$ & $2.0^{\circ}$ \\
$35,000 \mathrm{ft}$ & $\leq$ altitude $\leq$ & $65,000 \mathrm{ft}$ \\
\hline
\end{tabular}

In addition, note that the $\mathrm{NS}_{\mathrm{SS}-\mathrm{PT}}$ requires Eqs. (A2) for computing the sectional lift and moment forces, since the CFD surrogate is used to compute the force coefficients directly. Thus, in Eqs. (A2) only the piston theory pressure corrections are integrated:

$$
\begin{aligned}
& L=\int_{-b}^{b} q_{\infty}\left(\Delta C_{p, \mathrm{vel}}+\Delta \bar{C}_{p}\right) \mathrm{d} x+2 b q_{\infty} C_{L, \mathrm{SUR}_{\mathrm{SS}}} \\
& M_{E A}=-\int_{-b}^{b} q_{\infty}(x-b a)\left(\Delta C_{p, \mathrm{vel}}+\Delta \bar{C}_{p}\right) \mathrm{d} x \\
& \quad+(2 b)^{2} q_{\infty} C_{M, \mathrm{SUR}_{\mathrm{SS}}}+2 b a q_{\infty} C_{L, \mathrm{SUR}} \mathrm{SS}
\end{aligned}
$$

Surrogates were constructed for the coefficients of lift, $C_{L, \mathrm{SUR}}$ and moment, $C_{M, \mathrm{SUR}_{\mathrm{SS}}}$ for:

$$
\mathbf{x}=\left[\begin{array}{lll}
M_{\infty} & \alpha & \text { altitude }
\end{array}\right]
$$

where the coefficients of lift and moment (about the midchord) were computed for each snapshot using Eqs. (A4) and (A5):

$$
\begin{gathered}
C_{L_{\mathrm{SS}}}=\frac{1}{2 b} \int_{-b}^{b} \Delta C_{p} \mathrm{~d} x \\
C_{M_{\mathrm{SS}}}=-\frac{1}{(2 b)^{2}} \int_{-b}^{b} x \Delta C_{p} \mathrm{~d} x
\end{gathered}
$$

The accuracy of the surrogate was evaluated relative to a set of 50 Navier-Stokes computations of the lift and moment coefficients. These 50 test cases varied all three parameters simultaneously, at sampling points different from those used to construct the surrogate. A zero-order polynomial regression function and the Gaussian correlation function minimized the normalized $L_{\infty}$ and NRMSE for the above test cases. Furthermore, the kriging model of the static Navier-Stokes aerodynamic coefficients produced less than $4 \%$ maximum error and less than 1\% NRMSE, indicating a highly accurate surrogate for the CFD flow analysis. The computational time required to compute the static Navier-Stokes lift and moment coefficients was $\mathcal{O}\left(1 e^{-4} \mathrm{~s}\right)$.

\section{Acknowledgments}

This research is funded by the NASA Fundamental Aeronautics Program/Hypersonics Award NNX08AB32A with Don Soloway as Program Manager and Jorge Bardina as Technical Monitor. This work was supported in part by an allocation of computing time from the Ohio Supercomputer Center. Finally, the authors wish to express their gratitude to NASA Langley Research Center for the CFL3D code.

\section{References}

[1] Anderson, J. D., Jr., Hypersonic and High-Temperature Gas Dynamics, AIAA, Reston, VA, 2nd ed., 2006.

[2] Bille, M., Williams, T., and Villhard, V., "Reusable Space Vehicles: Lessons From Four Decades of Futility," AIAA Paper 2003-659, Jan. 2003.

[3] Mansour, N., Pittman, J., and Olson, L., "Fundamental Aeronautics Hypersonics Project: Overview," AIAA Paper 2007-4263, June 2007.

[4] Kazmar, R., "Airbreathing Hypersonic Propulsion at Pratt and WhitneyOverview," AIAA Paper 2005-3256, May 2005.

[5] Walker, S. H., and Rodgers, F., "Falcon Hypersonic Technology Overview," AIAA Paper 2005-3253, May 2005.

[6] Dolvin, D. J., "Hypersonic International Flight Research and Experimentation (HIFiRE) Fundamental Sciences and Technology Development Strategy,” AIAA Paper 2008-2581, April-May 2008.

[7] McClinton, C., "X-43 Scramjet Power Breaks the Hypersonic Barrier: Dryden Lectureship in Research for 2006," AIAA Paper 2006-1, Jan. 2006.

[8] Neuenhahn, T., Olivier, H., and Paull, A., "Development of the Hyshot Stability Demonstrator," AIAA Paper 2006-2960, April 1995.

[9] Bolender, M. A., and Doman, D. B., "Nonlinear Longitudinal Dynamic Model of an Air-Breathing Hypersonic Vehicle," Journal of Spacecraft and Rockets, Vol. 44, No. 2, March-April 2007, pp. 374-387. 
doi: $10.2514 / 1.23370$

[10] Ouzts, P., "The Joint Technology Office on Hypersonics," AIAA Paper 2008-2576, April 2008.

[11] Spottswood, S. M., Hollkamp, J. J., and Eason, T. G., "On the Use of Reduced-Order Models for a Shallow Curved Beam Under Combined Loading," AIAA Paper 2008-2235, April 2008.

[12] Ricketts, R. H., Noll, T. E., Whitlow, W., Jr., and Huttsell, L. J., "An Overview of Aeroelasticity Studies for the National Aero-Space Plane," AIAA Paper 1993-1313, April 1993.

[13] Gupta, K. K., Voelker, L. S., Bach, C., Doyle, T., and Hahn, E., "CFDBased Aeroelastic Analysis of the X-43 Hypersonic Flight Vehicle," AIAA Paper 2001-712, Jan. 2001.

[14] Berry, S. A., Horvath, T. J., Hollis, B. R., Thompson, R. A., and Hamilton, H. H., "X-33 Hypersonic Boundary Layer Transition," AIAA Paper 1999-3560, June-July 1999.

[15] Riley, C. J., Kleb, W. L., and Alter, S. J., "Aeroheating Predictions for X-34 Using an Inviscid-Boundary Layer Method," AIAA Paper 1999880, Jan. 1999.

[16] Bertin, J. J., Hypersonic Aerothermodynamics, AIAA, Reston, VA, 1994

[17] Blankson, I. M., "Air-Breathing Hypersonic Waveriders: A Survey of Research Needs," Proceedings of the First International Waverider Symposium, University of Maryland, College Park, MD, Oct. 1990.

[18] Bertin, J. J., and Cummings, R. M., "Fifty Years of Hypersonics: Where We've Been and Where We're Going," Progress in Aerospace Sciences, Vol. 39, April 2003, pp. 511-536. doi:10.1016/S0376-0421(03)00079-4

[19] Fidan, B., Mirmirani, M., and Ionnou, P., "Flight Dynamics and Control of Air-Breathing Hypersonic Vehicles: Review and New Directions," AIAA Paper 2003-7081, Dec. 2003.

[20] Cazier, F. W., Doggett, R., and Ricketts, R. H., "Structural Dynamic and Aeroelastic Considerations for Hypersonic Vehicles," AIAA Paper 1991-1255, April 1991.

[21] Dugundji, J., and Calligeros, J. M., "Similarity Laws for Aerothermoelastic Testing," Journal of the Aerospace Sciences, Vol. 29, No. 8, Aug. 1962, pp. 935-950.

[22] Lighthill, M. J., "Oscillating Airfoils at High Mach Numbers," Journal of the Aeronautical Sciences, Vol. 20, No. 6, June 1953, pp. 402-406.

[23] Ashley, H., and Zartarian, G., "Piston Theory-A New Aerodynamic Tool for the Aeroelastician," Journal of the Aeronautical Sciences, Vol. 23, No. 12, Dec. 1956, pp. 1109-1118.

[24] Van Dyke, M., "A Study of Second-Order Supersonic Flow Theory," NACA TR 1081, 1951.

[25] Morgan, H. G., Huckel, V., and Runyan, H. L., "Procedure for Calculating Flutter at High Supersonic Speed Including Camber Deflections, and Comparison with Experimental Results," NACA TN 4335, 1958.

[26] Zartarian, G., Hsu, P. T., and Ashley, H., "Dynamic Airloads and Aeroelastic Problems at Entry Mach Numbers," Journal of the Aeronautical Sciences, Vol. 28, No. 3, March 1961, pp. 209-222.

[27] Morgan, H. G., Runyan, H. L., and Huckel, V., "Theoretical Considerations of Flutter at High Mach Numbers," Journal of the Aeronautical Sciences, Vol. 25, No. 6, June 1958, pp. 371-381.

[28] Bisplinghoff, R. L., and Ashley, H., Principles of Aeroelasticity, Wiley, New York, 1962

[29] Heeg, J., Zeiler, T. A., Pototzky, A. S., Spain, C. V., and Engelund, W. C., "Aerothermoelastic Analysis of a NASP Demonstrator Model," AIAA Paper 1993-1366, April 1993.

[30] Rasmussen, M., Hypersonic Flow, Wiley, New York, 1994

[31] Nydick, I., Friedmann, P. P., and Zhong, X., "Hypersonic Panel Flutter Studies on Curved Panels," AIAA Paper 1995-1485, April 1995.

[32] Spain, C. V., Zeiler, T. A., Bullock, E. P., and Hodge, J. S., "A Flutter Investigation of All-Moveable NASP-Like Wings at Hypersonic Speeds," AIAA Paper 1993-1315, April 1993.

[33] Liu, D. D., Yao, Z. X., Sarhaddi, D., and Chavez, F., "From Piston Theory to a Unified Hypersonic-Supersonic Lifting Surface Method,' Journal of Aircraft, Vol. 34, No. 3, May-June 1997, pp. 304-312. doi:10.2514/2.2199

[34] McNamara, J. J., Friedmann, P. P., Powell, K. G., Thuruthimattam, B. J., and Bartels, R. E., "Aeroelastic and Aerothermoelastic Behavior in Hypersonic Flow,” AIAA Journal, Vol. 46, No. 10, Oct. 2008, pp. 2591 2610. doi: $10.2514 / 1.36711$

[35] Thuruthimattam, B. J., Friedmann, P. P., Powell, K. G., and Bartels, R. E., "Computational Aeroelastic Studies of a Generic Hypersonic Vehicle," The Aeronautical Journal, Vol. 113, No. 1150, Dec. 2009, pp. 763-774.
[36] Scott, R. C., and Pototzky, A. S., "Quasisteady Aerodynamics for Flutter Analysis Using Steady Computational Fluid Dynamics Calculations," Journal of Aircraft, Vol. 33, No. 1, Jan.-Feb. 1996, pp. 191-197. doi:10.2514/3.46921

[37] Crowell, A. R., McNamara, J. J., Kecskemety, K. M., and Goerig, T., "A Reduced Order Aerothermodynamic Modeling Framework for Hypersonic Aerothermoelasticity," AIAA Paper 2010-2969, April 2010.

[38] Bisplinghoff, R. L., Ashley, H., and Halfman, R. L., Aeroelasticity, Addison-Wesley, Cambridge, MA, 1955.

[39] McNamara, J. J., Gogulapati, A., Friedmann, P. P., and Banavara, N. K., "Approximate Modeling of Unsteady Aerodynamic Loads in Hypersonic Aeroelasticity," International Forum on Aeroelasticity and Structural Dynamics, Paper 2007-099, Stockholm, June 2007.

[40] Zhang, W. W., Ye, Z. Y., Zhang, C. A., and Liu, F., "Supersonic Flutter Analysis Based on Local Piston Theory," AIAA Journal, Vol. 47, No. 10, Oct. 2009, pp. 2321-2328. doi:10.2514/1.37750

[41] Hayes, W. D., and Probstein, R. F., Hypersonic Flow Theory, 1st ed., Academic Press, New York, 1959.

[42] McNamara, J. J., Friedmann, P. P., Powell, K. G., Thuruthimattam, B. J., and Bartels, R. E., "Three-Dimensional Aeroelastic and Aerothermoelastic Behavior in Hypersonic Flow," AIAA Paper 2005-2175, April 2005.

[43] Yates, E., and Bennett, R., "Analysis of Supersonic-Hypersonic Flutter of Lifting Surfaces at Angle of Attack," AIAA Paper 1971-327, April 1971.

[44] Anderson, J. D., Jr., Modern Compressible Flow with Historical Perspective, 3rd ed., McGraw-Hill, New York, 2003.

[45] Cox, R. N., and Crabtree, L. F., Elements of Hypersonic Aerodynamics, English Universities Press, London, 1965.

[46] Krist, S. L., Biedron, R. T., and Rumsey, C. L., "CFL3D User's Manual (Version 5.0)," NASA TM 1998-208444, 1997; also CFL3D Version 6.4, Oct. 2005.

[47] Bartels, R. E., Rumsey, C. L., and Biedron, R. T., "CFL3D User's Manual-General Usage and Aeroelastic Analysis (Version 6.4)," NASA TM 2006-214301, 2006.

[48] McNamara, J. J., and Friedmann, P. P., "Flutter-Boundary Identification for Time-Domain Computational Aeroelasticity," AIAA Journal, Vol. 45, No. 7, July 2007, pp. 1546-1555. doi:10.2514/1.26706

[49] Cunningham, H. J., Batina, J. T., and Bennett, R. M., "Modern Wing Flutter Analysis by Computational Fluid Dynamic Methods," Journal of Aircraft, Vol. 25, No. 10, 1988, pp. 962-968. doi:10.2514/3.45686

[50] Robinson, B. A., Batina, J. T., and Yang, H. T., "Aeroelastic Analysis of Wings Using the Euler Equations with a Deforming Mesh," Journal of Aircraft, Vol. 28, No. 11, Nov. 1991, pp. 781-788. doi:10.2514/3.46096

[51] Pak, C. G., and Friedmann, P. P., "New Time Domain Technique for Flutter Boundary Identification," AIAA Paper 1992-2102, April 1992.

[52] Torii, H., and Matsuzaki, Y., "Flutter Margin Evaluation for DiscreteTime Systems," Journal of Aircraft, Vol. 38, No. 1, Jan.-Feb. 2001, pp. 42-47. doi: $10.2514 / 2.2732$

[53] McNamara, J. J., and Friedmann, P. P., "Aeroelastic and Aerothermoelastic Analysis of Hypersonic Vehicles: Current Status and Future Trends," AIAA Paper 2007-2013, April 2007.

[54] Heeg, J., Gilbert, M. G., and Pototzky, A. S., "Active Control of Aerothermoelastic Effects for a Conceptual Hypersonic Aircraft," Journal of Aircraft, Vol. 30, No. 4, July-Aug. 1993, pp. 453-458. doi: $10.2514 / 3.56890$

[55] Sacks, J., Welch, W. J., Mitchell, T. J., and Wynn, H. P., "Design and Analysis of Computer Experiments," Statistical Science, Vol. 4, No. 4, 1989, pp. 409-435. doi:10.1214/ss/1177012413

[56] Simpson, T. W., Mauery, T. M., Korte, J. J., and Mistree, F., "Kriging Models for Global Approximation in Simulation-Based Multidisciplinary Design Optimization," AIAA Journal, Vol. 39, No. 12 , Dec. 2001, pp. 2233-2241. doi: $10.2514 / 2.1234$

[57] Chung, H. S., and Alonso, J. J., "Comparison of Approximation Models with Merit Functions for Design Optimization," AIAA Paper 20004754, Sept. 2000.

[58] Lophaven, S. N., Nielsen, H. B., and Sondergaard, J., "DACE A MATLAB Kriging Toolbox Version 2.0," IMM Technical Report TR2002-12, 2002. 
[59] Crowell, A. R., Culler, A. J., and McNamara, J. J., "Reduced Order Aerothermodynamics for Two-way Coupled Aerothermoelasticity in Hypersonic Flow,' International Forum on Aeroelasticity and Structural Dynamics, Paper 2009-094, Seattle, WA, June 2009.

[60] Kolonay, R. M., and Lambe, L. A., "Determination of the Optimal Set of Parameters of a Kriging Model for an Euler Based Induced Drag Function," International Forum on Aeroelasticity and Structural Dynamics, Paper 2009-005, Seattle, WA, June 2009.

[61] Kumano, T., Jeong, S., Obayashi, S., Ito, Y., Hatanaka, K., and
Morino, H., "Multidisciplinary Design Optimization of Wing Shape for a Small Jet Aircraft Using Kriging Model,” AIAA Paper 2006-932, Jan. 2006.

[62] Lam, X. B., Kim, Y. S., Hoang, A. D., and Park, C. W., "Coupled Aerostructural Design Optimization Using the Kriging Model and Integrated Multiobjective Optimization Algorithm," Journal of Optimization Theory and Applications, Vol. 142, No. 3, Sept. 2009, pp. 533-556.

doi:10.1007/s10957-009-9520-9 